\title{
Functional Role of Natural and Synthetic Scaffolds in Tissue Engineering of Central Nervous System
}

\section{Parastoo Barati Dowom ${ }^{1,2}$, Kambiz Roshanaei², Sajad Sahab Negah ${ }^{1}$, Hadi Aligholi ${ }^{1}$, Fatemeh Alipour ${ }^{1}$, Marzieh Darvishi $^{*}$}

'Shefa Neuroscience Research Center, Khatam Alanbia Hospital, Tehran, Iran ${ }^{2}$ Department of Physiology, Faculty of Sciences, Qom Branch, Islamic Azad University of Qom, Qom, Iran

${ }^{3}$ Department of Anatomy, Faculty of Medicine, Ilam University of Medical Sciences, Ilam, Iran

\section{A BSTRACT}

Introduction: Due to lack of replacement of lost cells and neural factors in the affected area, regeneration and repair in the nervous system is complicated and has been of interest to researchers in recent years. Extensive studies in this field, such as cell therapy and tissue engineering methods, have provided novel approaches for nerve regeneration. The use of neural stem cells and scaffolds with sub-micron and nano-sized fiber structure similar to the natural extracellular matrix are the perfect choice for nervous tissue engineering. To this end two-dimensional (2D) and three-dimensional (3D) cultures have been used. 2D cell culture has been performed in hundreds of laboratories during the last two decades. This method of culture is elementary and does not reproduce the anatomy or physiology of a tissue for useful study. Therefore, a new method is needed to mimics the cell function and tissue architecture. Although design of 3D cell culture systems is more relevant, there are still several hurdles that must be overcome. When to be mentioned the 3D, investigators require for consider the design of matrix for supporting and proliferation of the cells. In general, scaffolds have been categorized in three groups, including natural, synthetic, and hybrid (natural \& synthetic). Scaffolds combined with any chemical or physical properties are suitable for tissue engineering of the central nervous system if they are non-toxic, with size fiber of 200-600 nm, with the gradual degradation of the scaffold after implantation in the body, and with capability of cell growth and proliferation. Conclusion: Recent investigations demonstrated that 3D culture is more mature and relevant to human and animal physiology than 2D cell culture. The hybrid scaffolds are best choice for fiber diameter size and high capacity of cell proliferation. The purpose of this review is to provide a general overview of scaffold design by natural and synthetic polymers and their effects on regeneration of the central nervous system.

\section{*Corresponding Author: Marzieh Darvishi}

E-mail: Marzidarvish@yahoo.com 


\section{نقش كاربردى داربستهاى طبيعى و صناعى در مهندسى بافت سيستم عصبى مركزى}

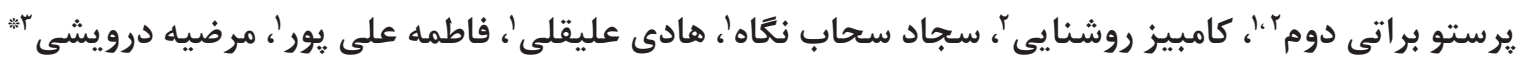

'مركزتحقيقات علوم اعصاب شفا، بيمارستان خاتمالانبياء، تهران، ايران

rكروه فيزيولوزى، دانشكده علوم پايه، واحد قم، دانشعاه آزاد اسلامى قم، قم، ايران

"َّروه آناتومى، دانشكده يزشكى، دانشعاه علوم يزشكى ايلام، ايلام، ايران

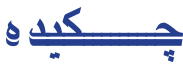

مقدمه: با توجه به عدم جايكزينى سلولهاى از دست رفته و عوامل عصبى در ناحيئ تحت تأثير واقع

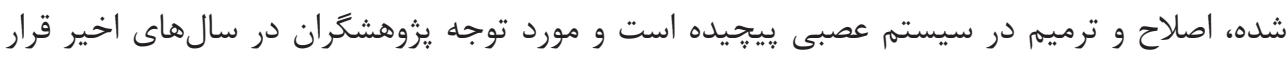

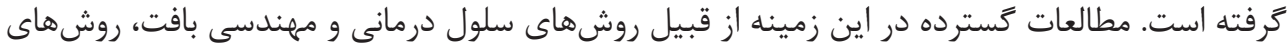

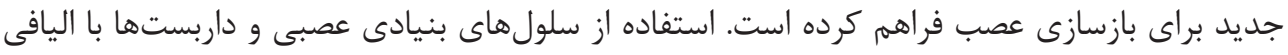

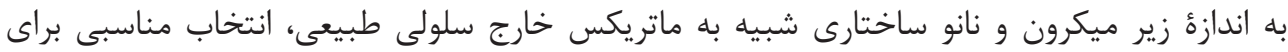

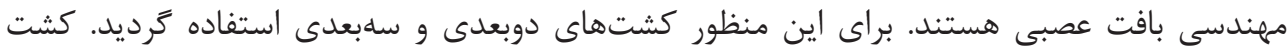

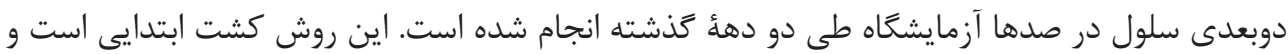

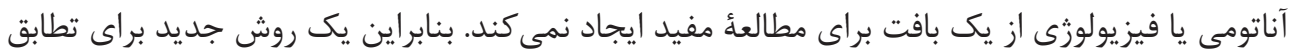

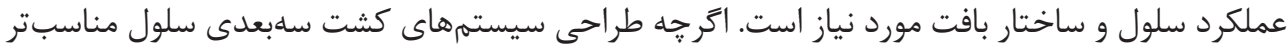

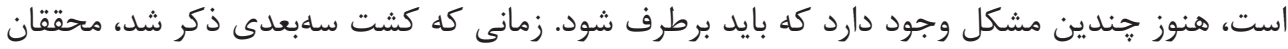

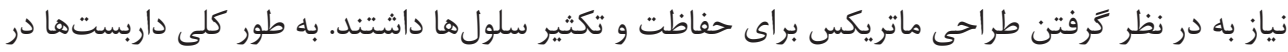

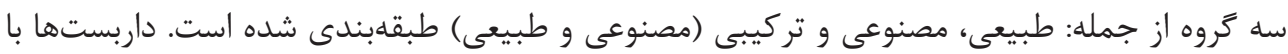

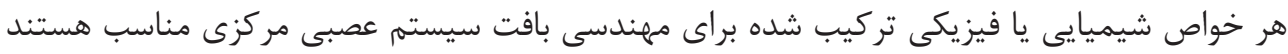

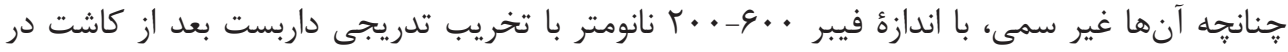

كليد وازهها:

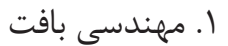

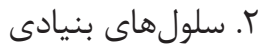

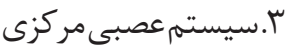

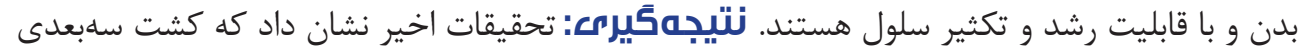

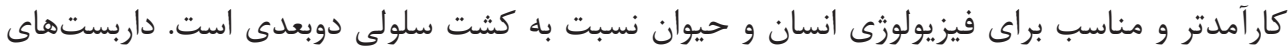

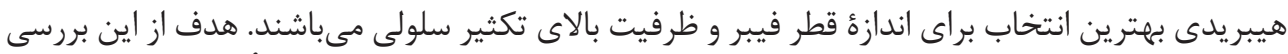

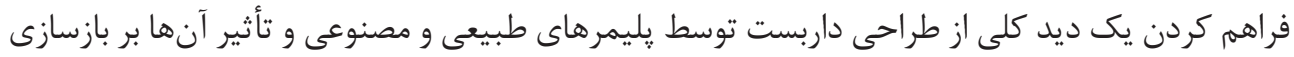
سيستمم عصبى مركزى است. 


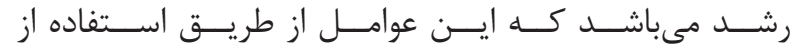

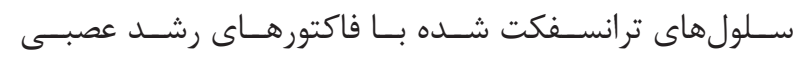

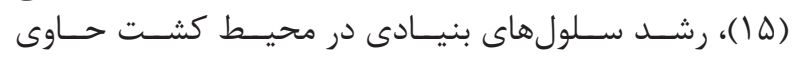

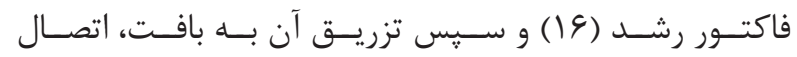

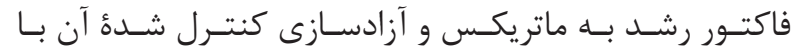

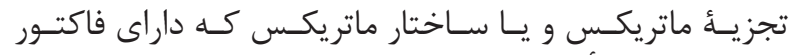

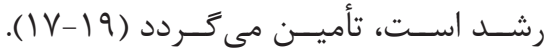

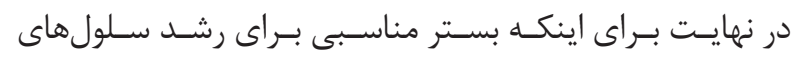

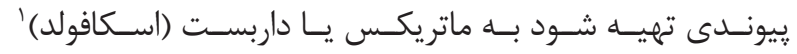

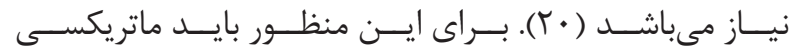

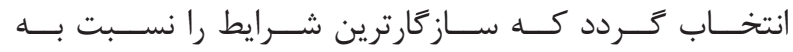

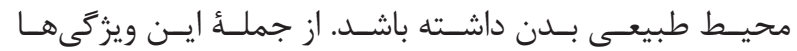

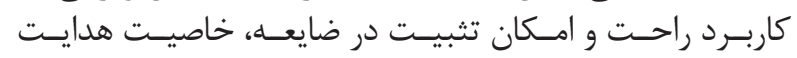

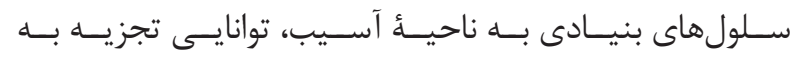

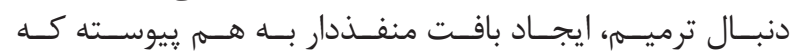

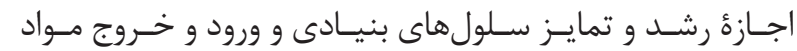

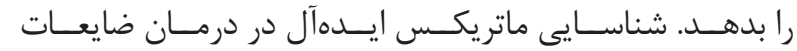

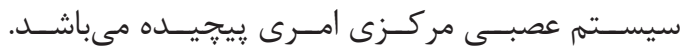

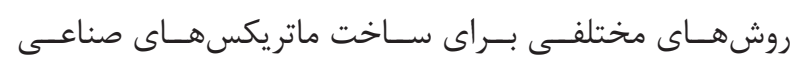

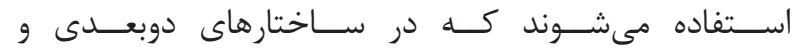

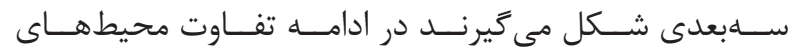

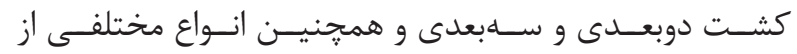

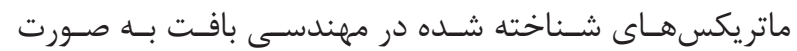

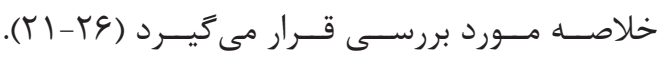

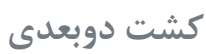

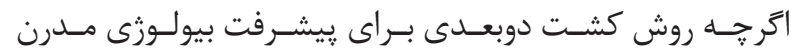

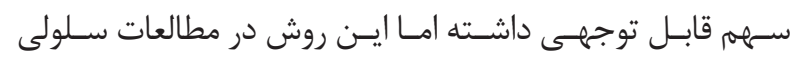

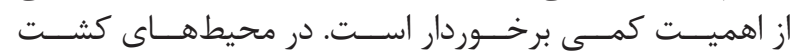

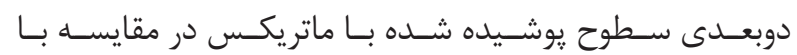

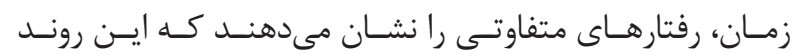

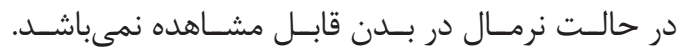

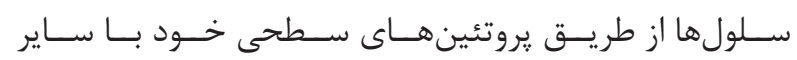

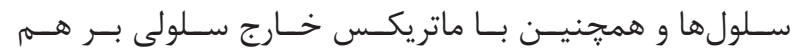

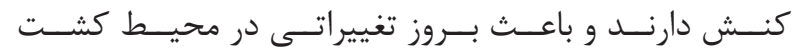

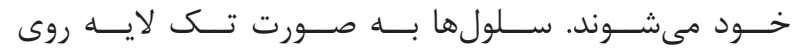

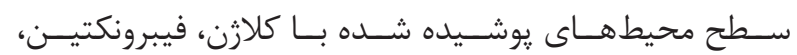

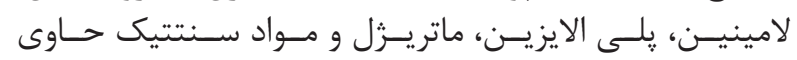

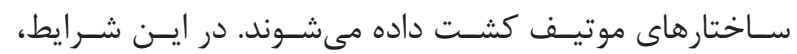

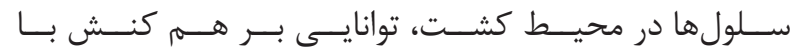

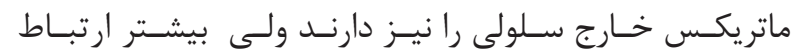

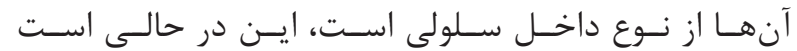

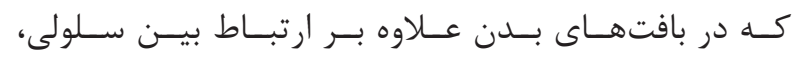

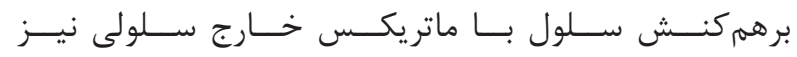

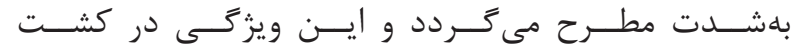

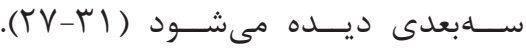

مقدمه

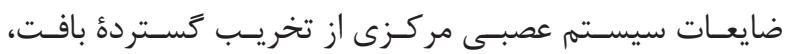

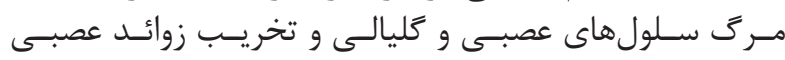

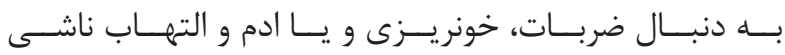

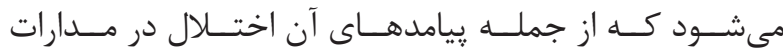

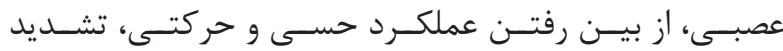

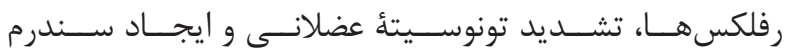

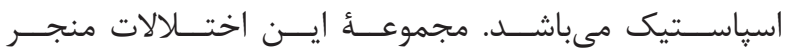

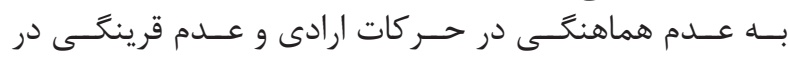

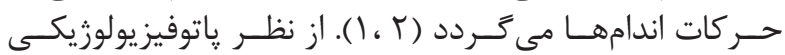

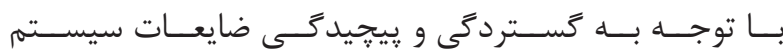

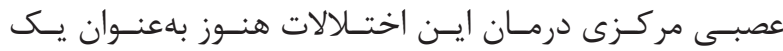

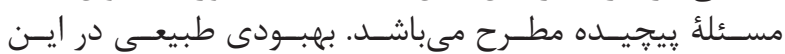

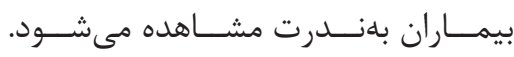

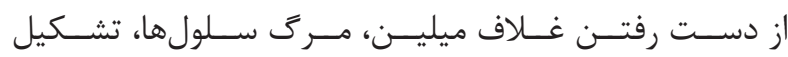

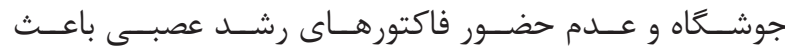

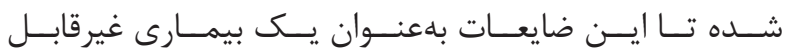

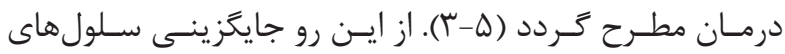

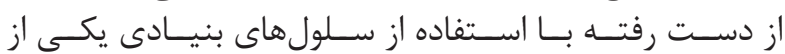

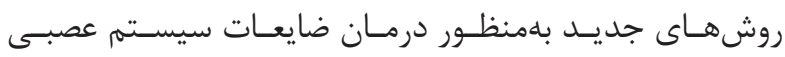

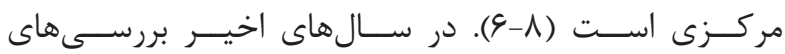

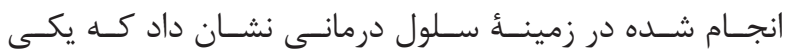

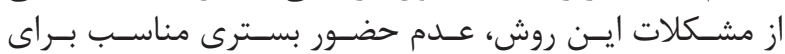

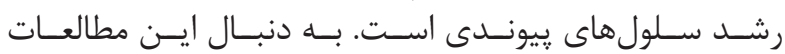

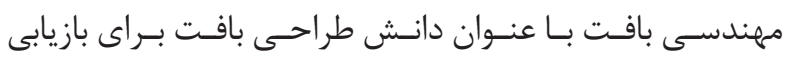

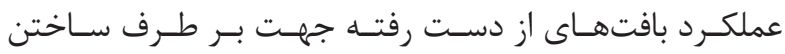

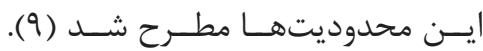

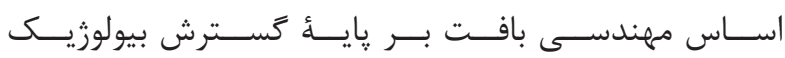

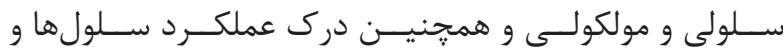

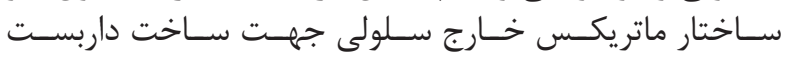

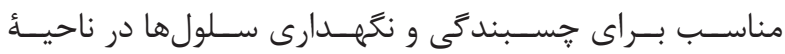

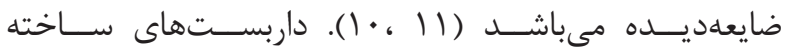

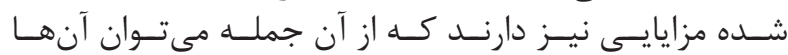

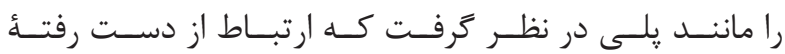

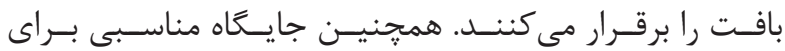

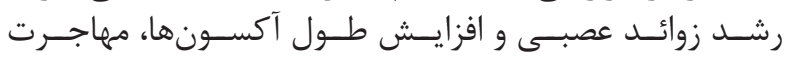

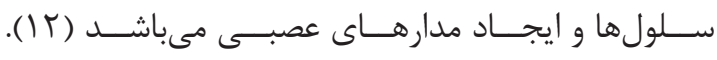

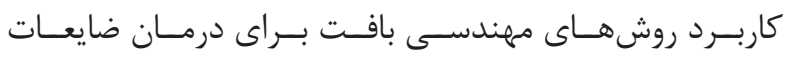

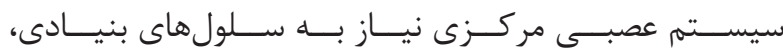

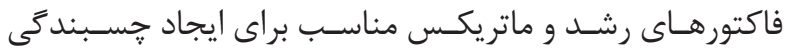

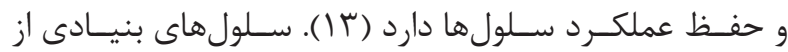

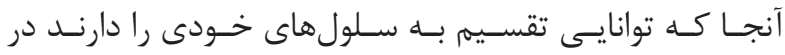

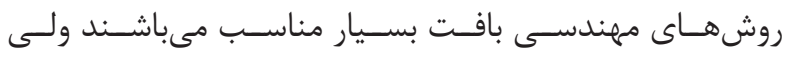

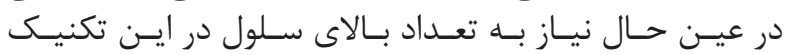

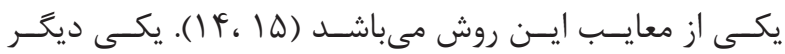

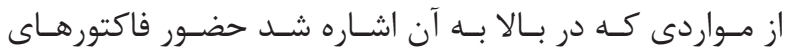

${ }^{1}$ Scaffold 
ويثَّى داربست هاى بيولوزيك ايده آل

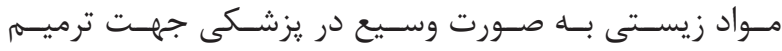

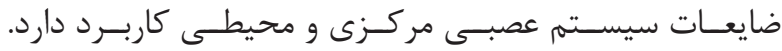

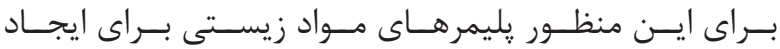

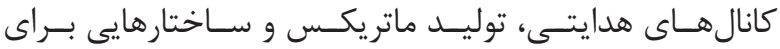

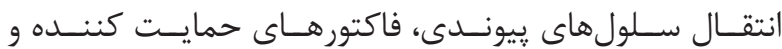

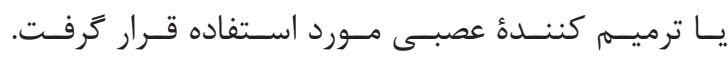

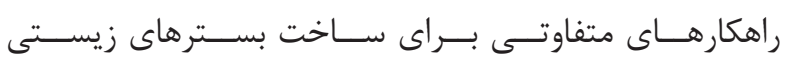

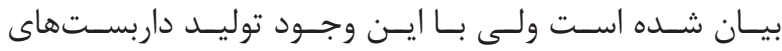

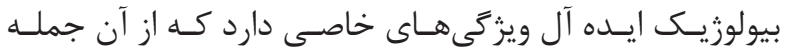

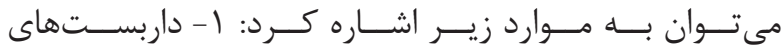

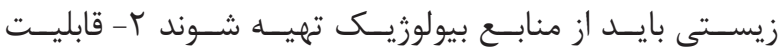

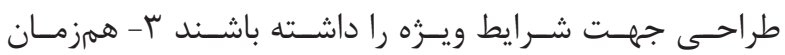

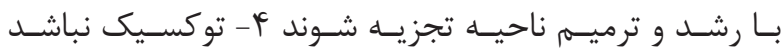

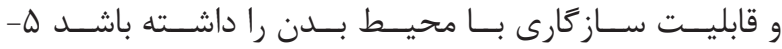

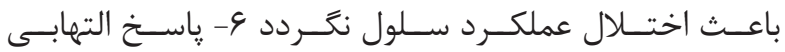

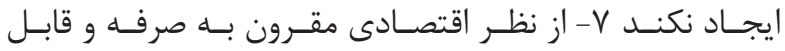

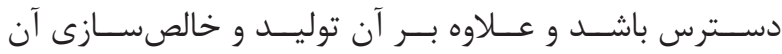

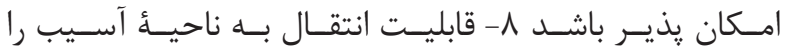

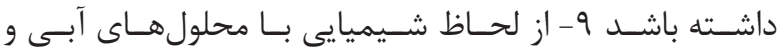

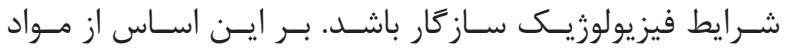

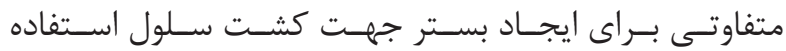

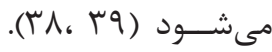

رايجترين داربستهاى مورد استفاده در مهيندسى بافت عصبيى

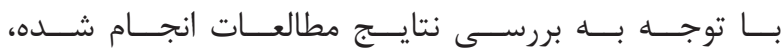

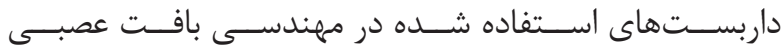

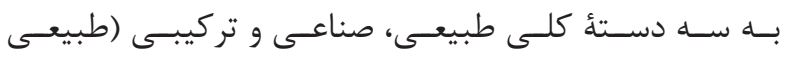

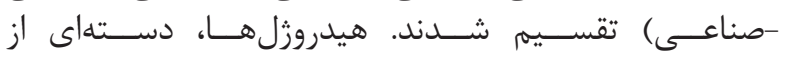

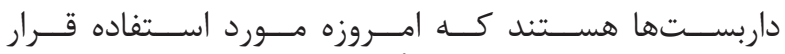

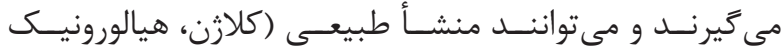

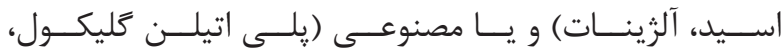

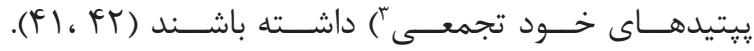

$$
\text { داربستهاي طبيعى }
$$

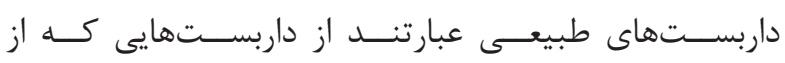

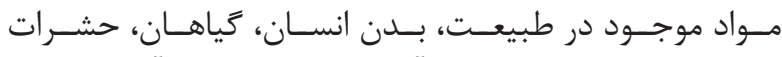

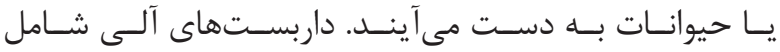

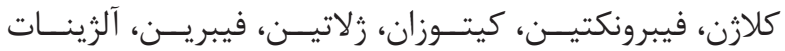

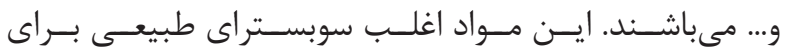

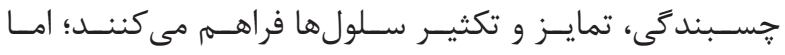

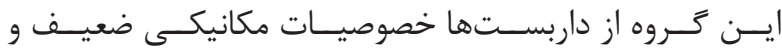

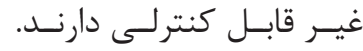

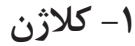

از يروتئينهــــ اصلـى ماتريكـس خــارج ســلولى بـوده، از

${ }^{2}$ Signaling

${ }^{3}$ Self-assembling
در سيسـتم كشــت دوبعـدى سـايتوكينها، كموكينهــا

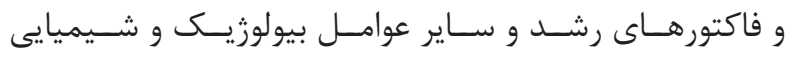

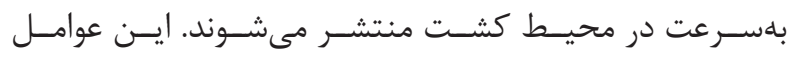

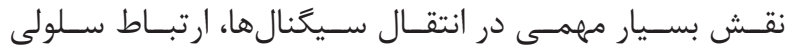

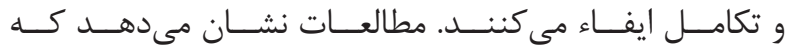

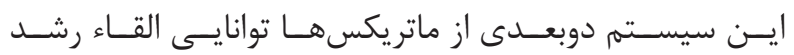

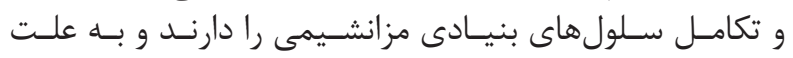

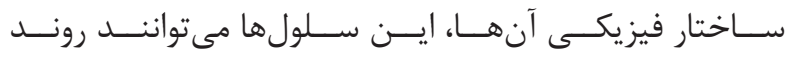

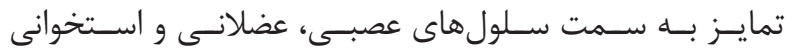

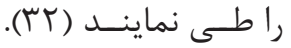

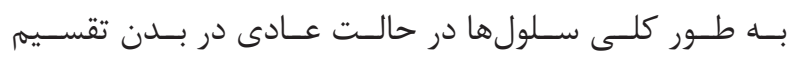

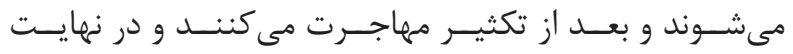

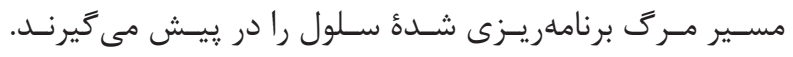

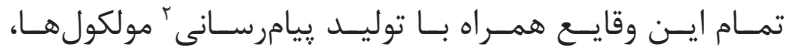

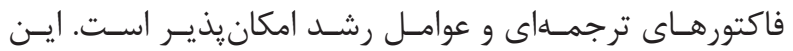

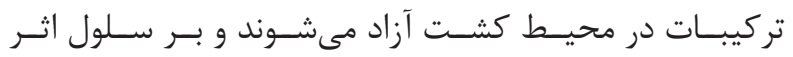

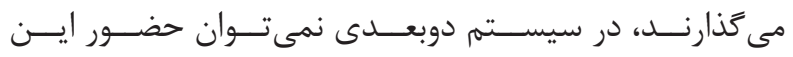

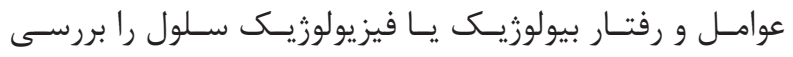

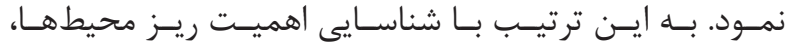

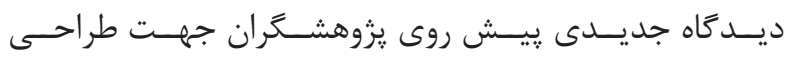

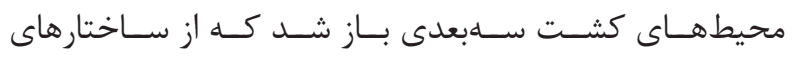

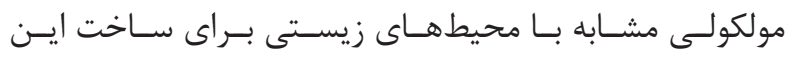

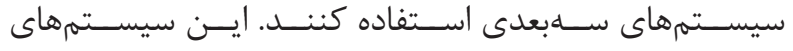

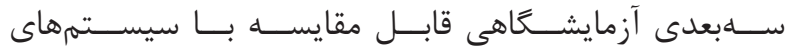

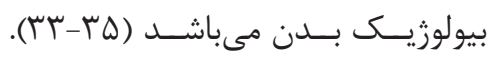

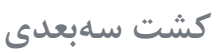

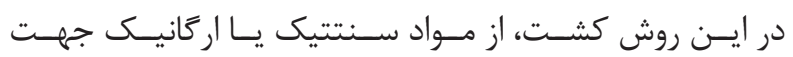

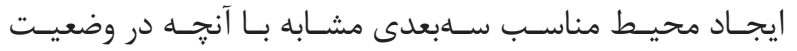

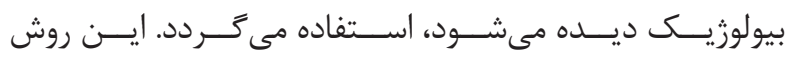

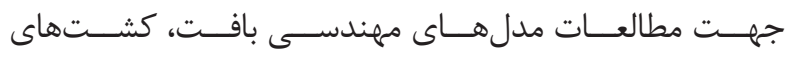

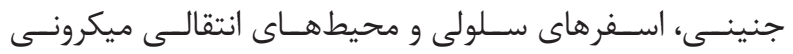

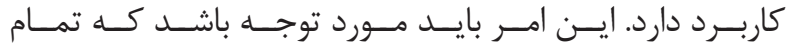

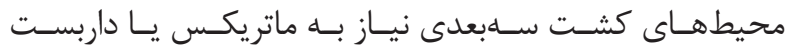

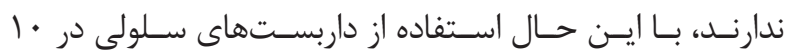

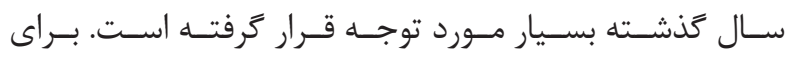

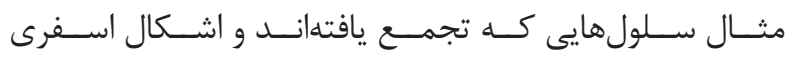

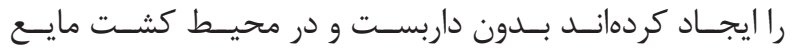

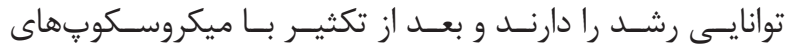

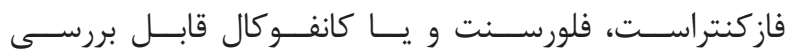

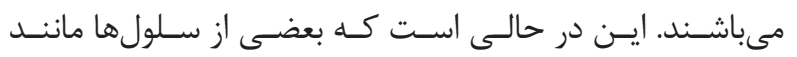

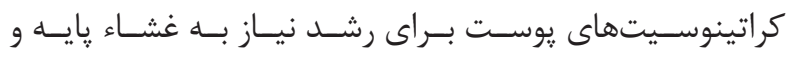

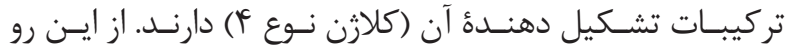

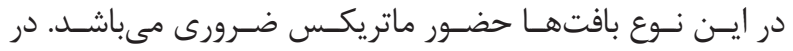

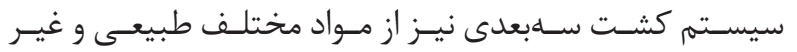

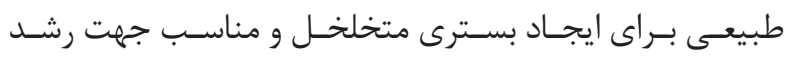

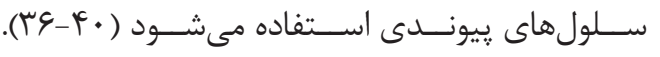




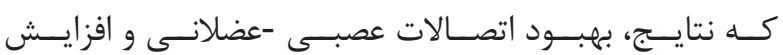

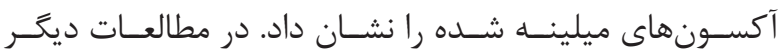

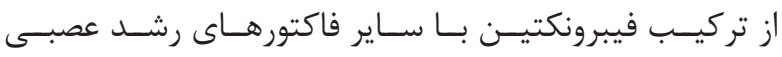

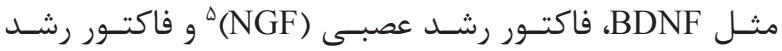

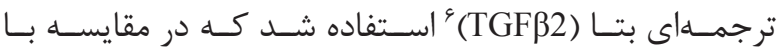

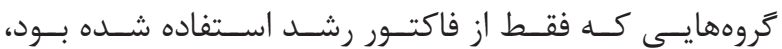

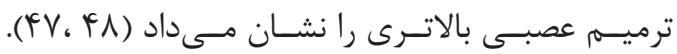
ب- آلثينات

هلـى سـاكاريد خطـى اسـت كـهـ از جلبـك دريايسى اسـتخراج

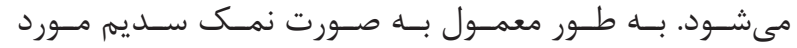

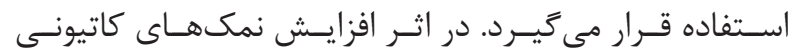

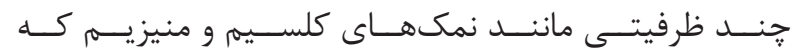

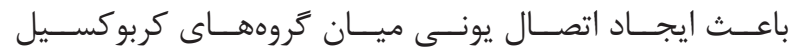

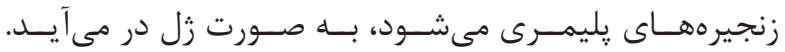

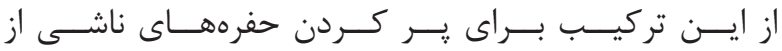

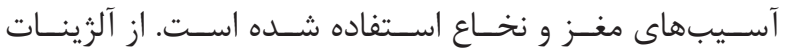

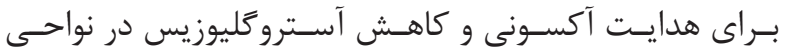

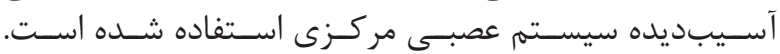

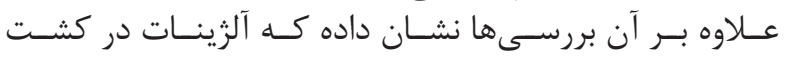

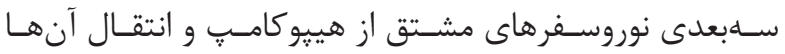

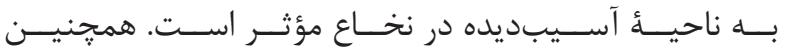

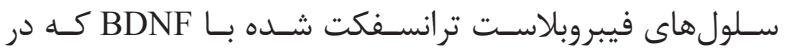

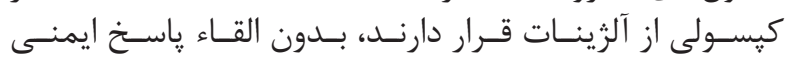

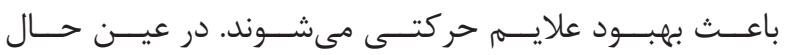

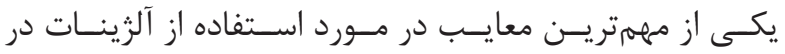

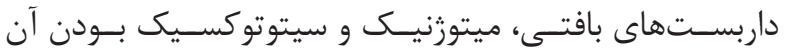

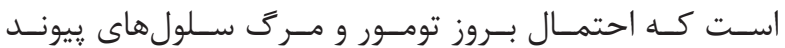

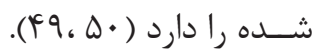

\section{P - Pيالورونيك اسيد}

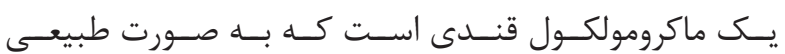

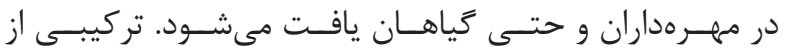

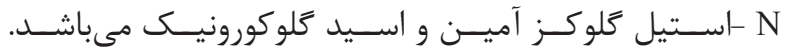

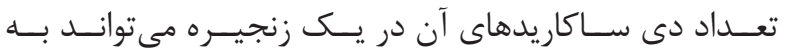

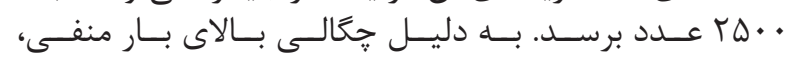

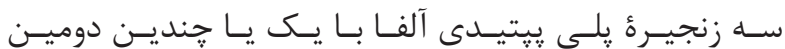

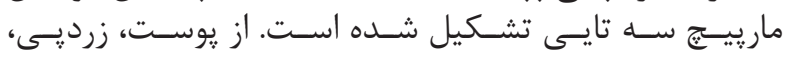

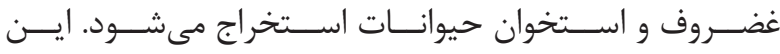

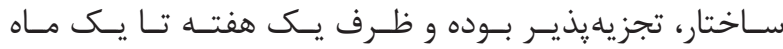

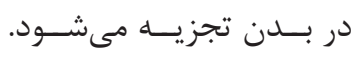

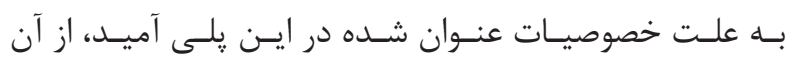

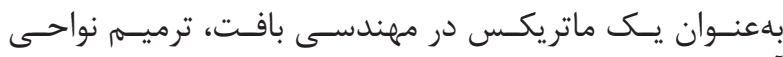

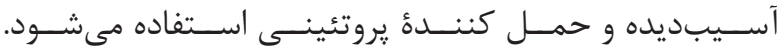

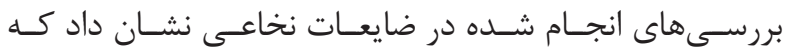

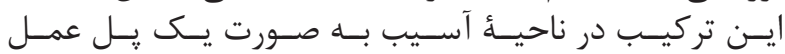

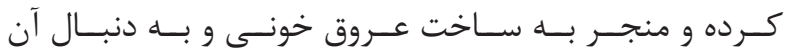

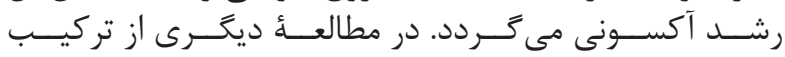

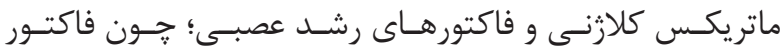

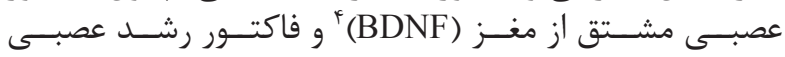

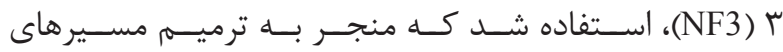

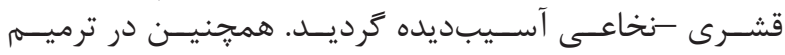

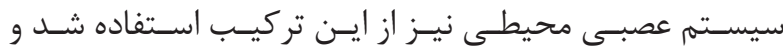

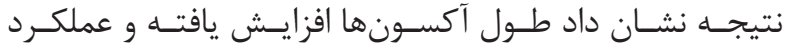

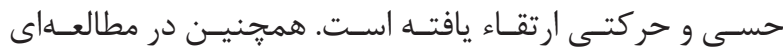

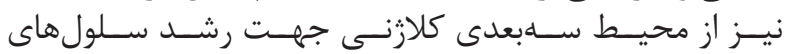

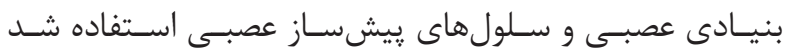

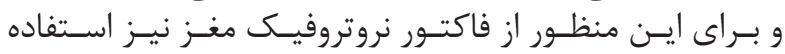

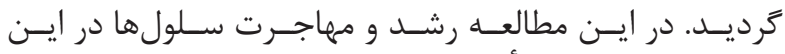

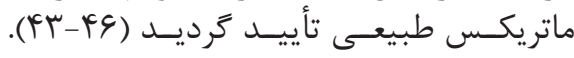

$$
\text { r- فيبرونكتين }
$$

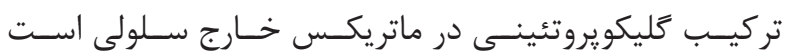

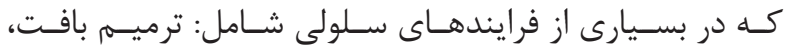

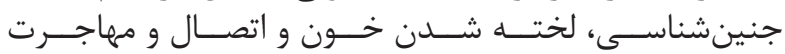

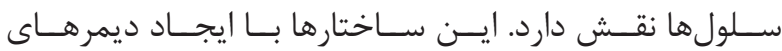

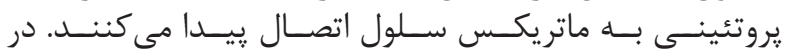

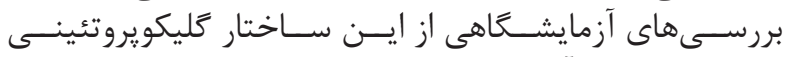

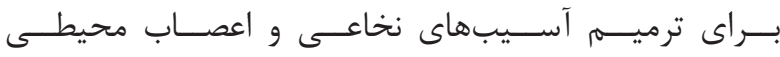

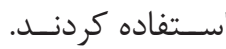

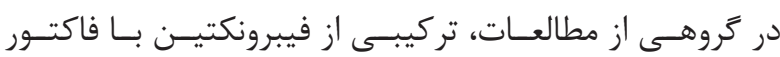

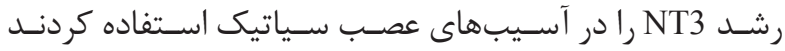

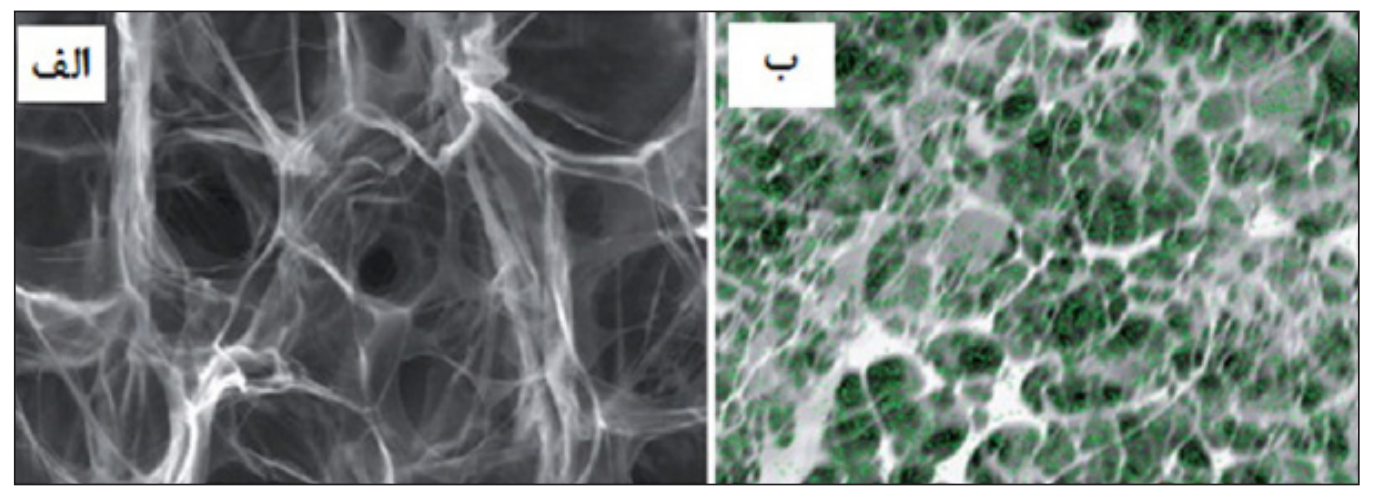

تصوير ا- مقايسٔ تصاوير ميكروسكوب الكترونى اسكنيً از داربستهاى كلارثى (الف) و داربست كلارنى اسيد هيالورونيك (به).

${ }^{4}$ Brain-derived neurotrophic factor

${ }^{5}$ Nerve growth factor

${ }^{6}$ Transforming growth factor beta- 2 


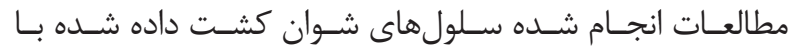

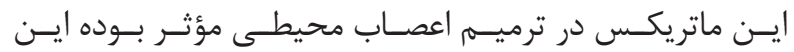

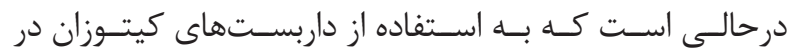

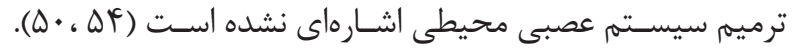

\section{9- يلى بتا هيدركسى بوترات}

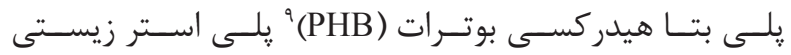

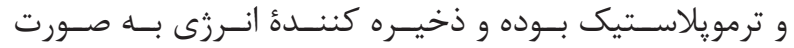

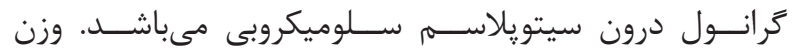

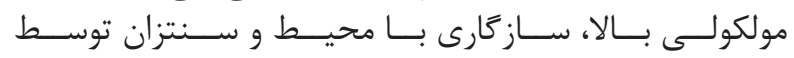

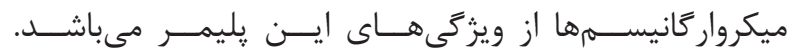

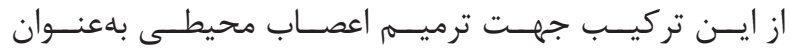

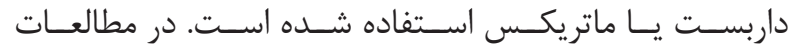

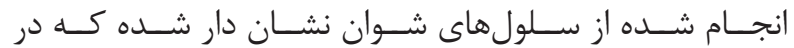

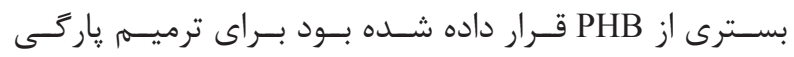

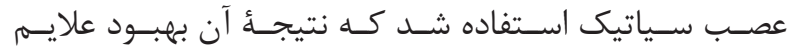

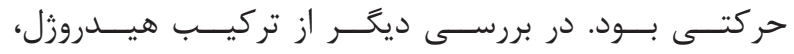

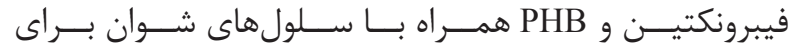

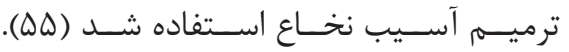

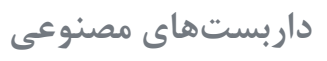

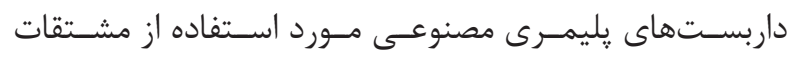

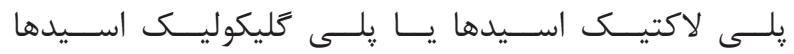

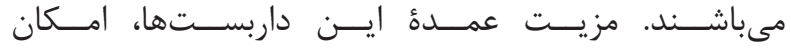

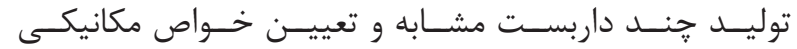

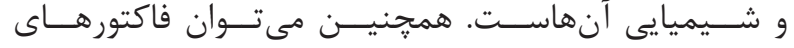

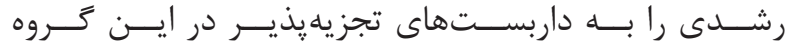

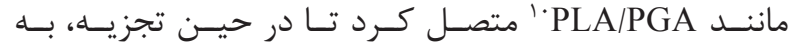

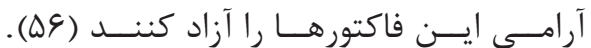

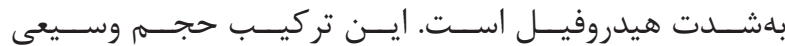

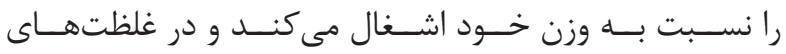

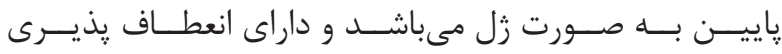

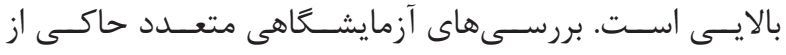

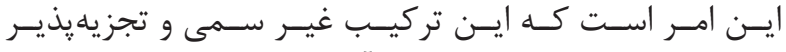

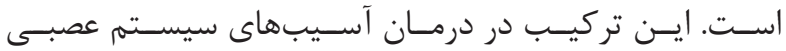

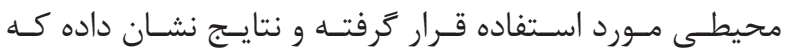

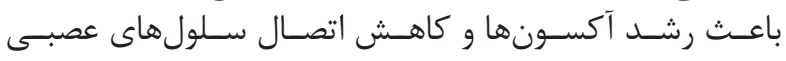

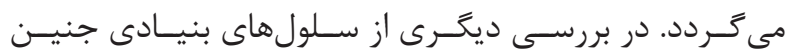

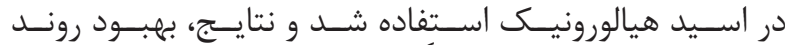

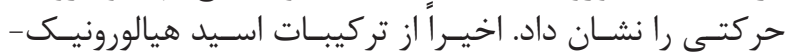

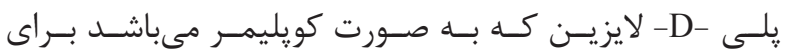

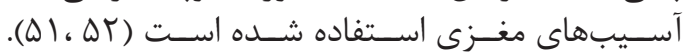

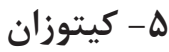

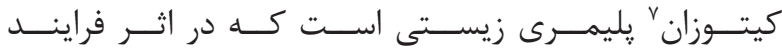

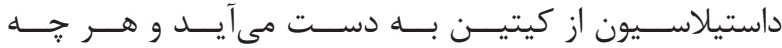

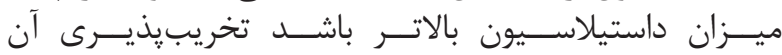

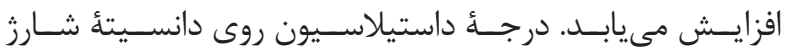

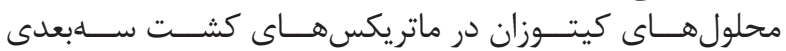

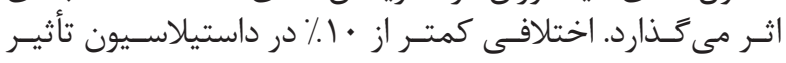

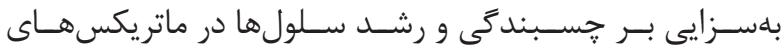

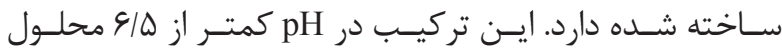

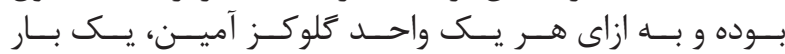

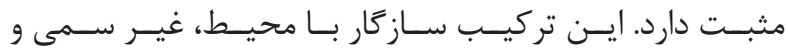

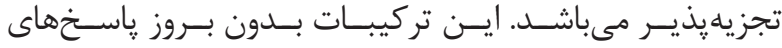

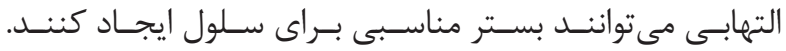

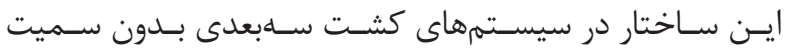

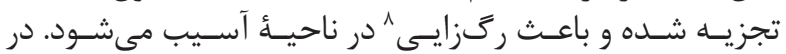

جدول ا- انواع داربستهاى طبيعى و كاربرد آنها در ترميم آسيبهاى سيستم عصبى مركزى.

\begin{tabular}{|c|c|c|}
\hline \multicolumn{3}{|c|}{ انواع داربستهاى طبيعى } \\
\hline 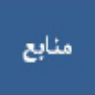 & كاربرد داربستهان طبيعى دز سيستم عصبى مركزى & 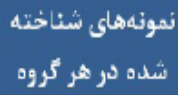 \\
\hline (Ff) & 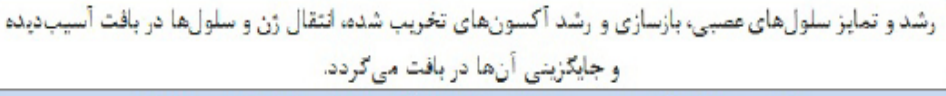 & كلاثن \\
\hline$\left(* \gamma_{0}+\Lambda\right)$ & 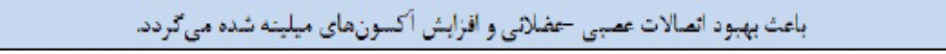 & فيبرونكتين \\
\hline$(* a, \Delta \cdot)$ & 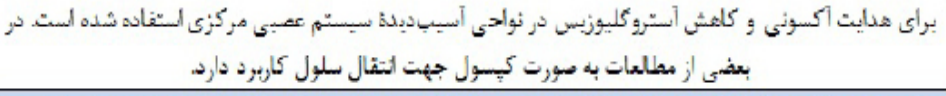 & 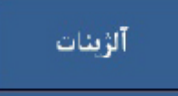 \\
\hline$(\Delta l, \Delta r)$ & 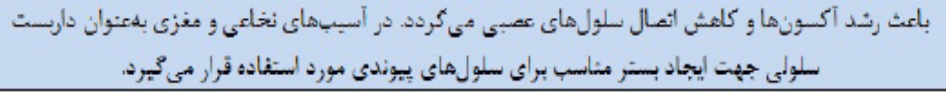 & 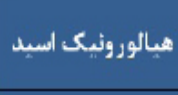 \\
\hline$(\Delta \cdot \Delta F)$ & 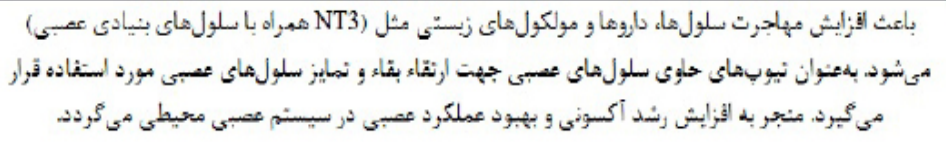 & 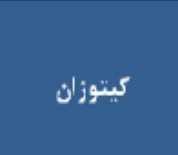 \\
\hline$(\Delta \Delta)$ & 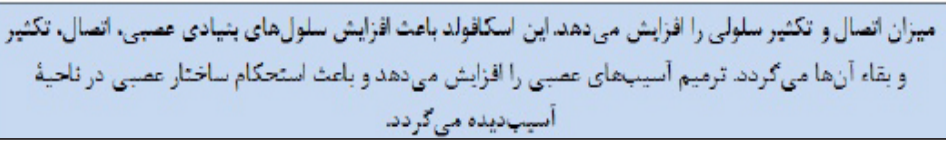 & 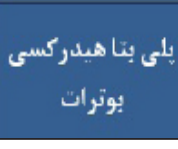 \\
\hline
\end{tabular}

Chitosan

${ }^{8}$ Angiogenesis
${ }^{9}$ Polyhydroxybutyrate

${ }^{10}$ Poly lactic acid/polyethylene glycol acid 


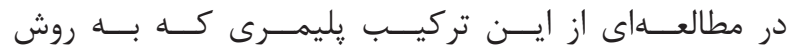

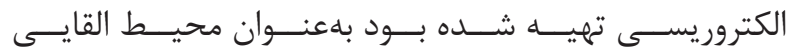

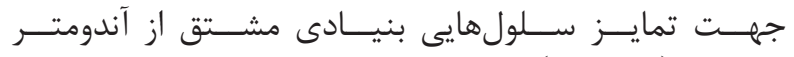

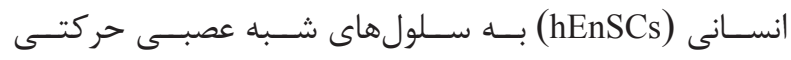

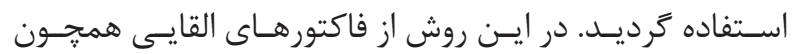

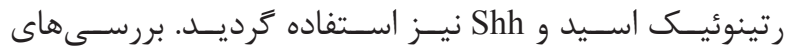

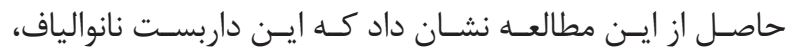

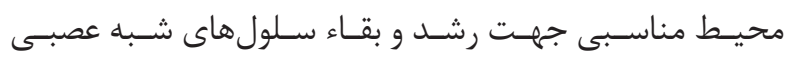

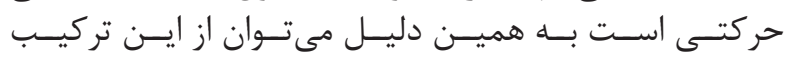

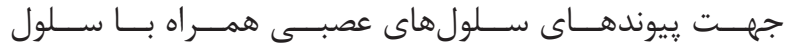

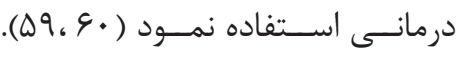

$$
\text { ب- يلى كايرولاكتون }
$$

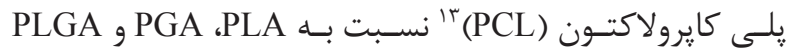

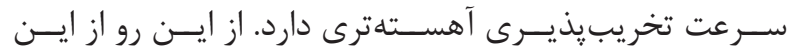

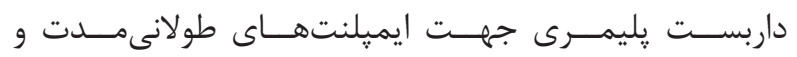

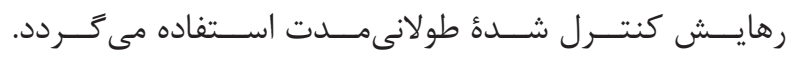

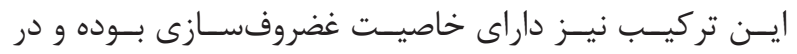

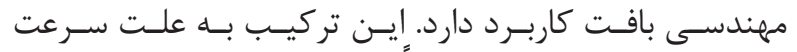

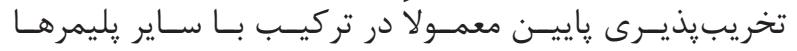

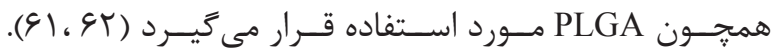

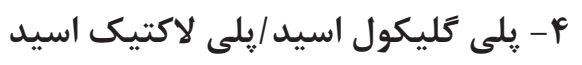

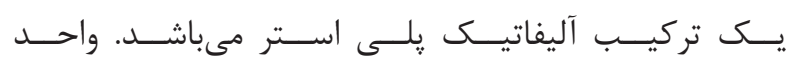

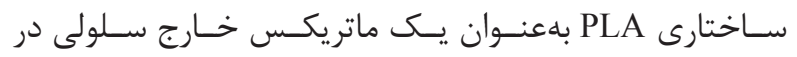

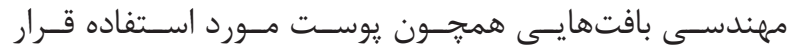

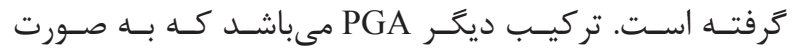

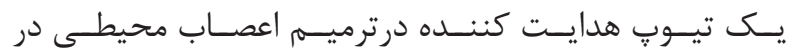

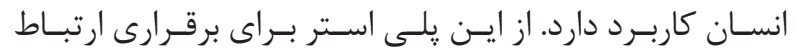

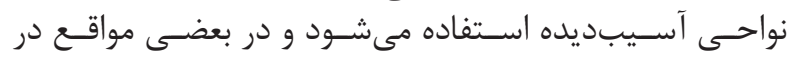

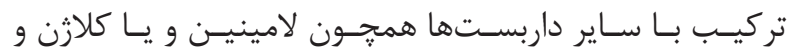

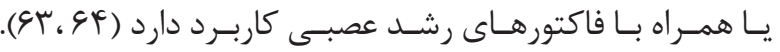

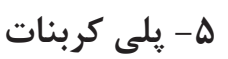

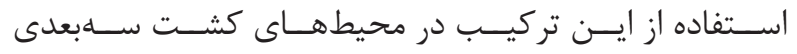

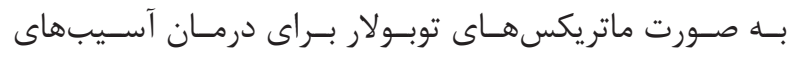

\section{ا- يلى لاكتيك اسيد}

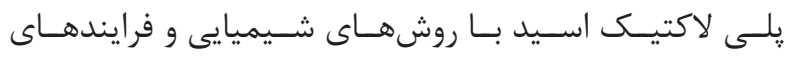

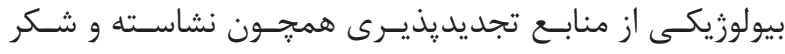

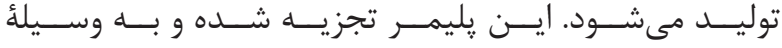

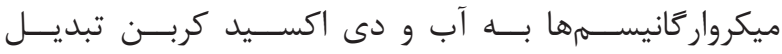

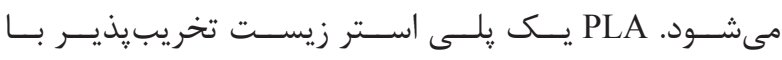

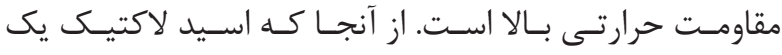

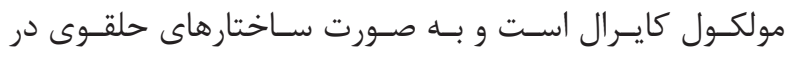

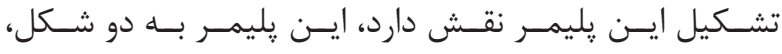
D-PLA

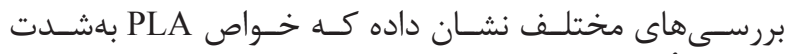

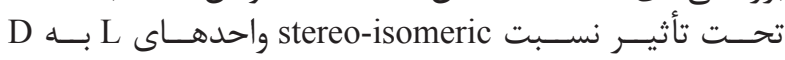

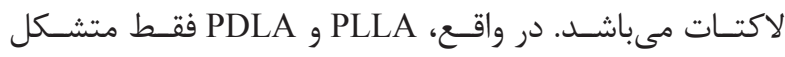

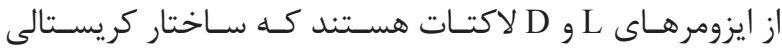

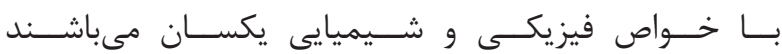

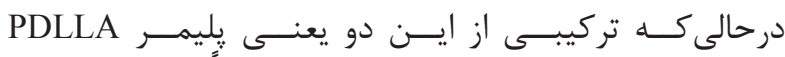

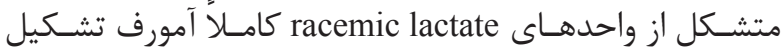

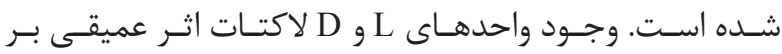

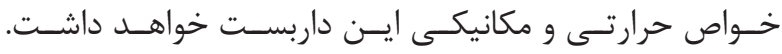

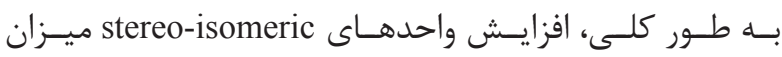

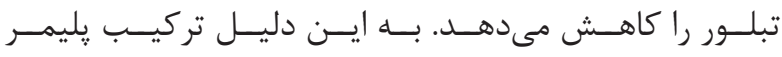

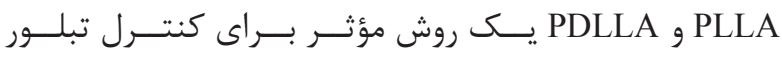

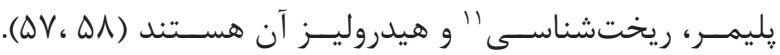

\section{ץ- كو يليمر يلى لاكتيد كوَلايكوليك اسيد}

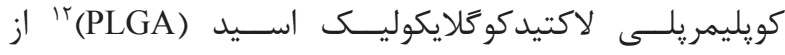

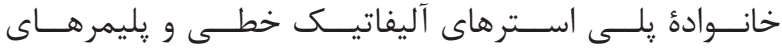

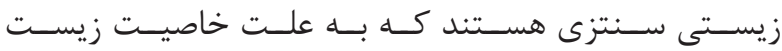

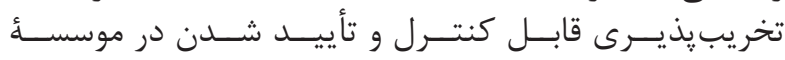

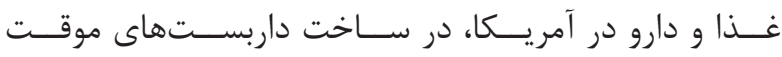

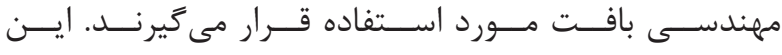

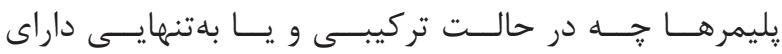

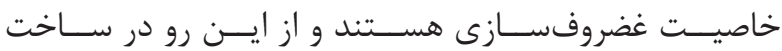

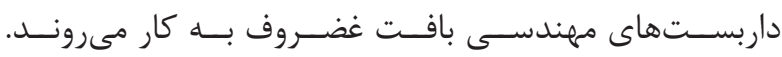

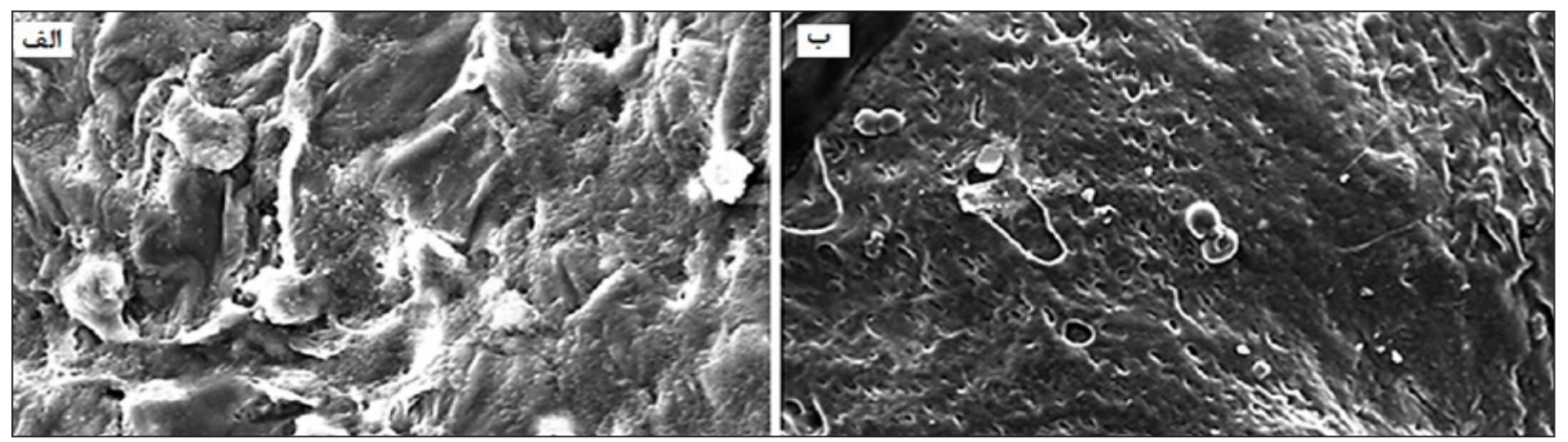

تصوير r- مقايسٔ تصاوير ميكروسكوب الكترونى اسكنينً از داربست تركيبى (كيتوزان + PLA) و صناعى (PLA)-(\$D).

${ }^{11}$ Morphology

${ }^{12}$ Poly lactic co- glycolic acid

${ }^{13}$ Polycaprolactone 


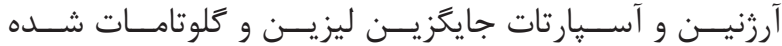

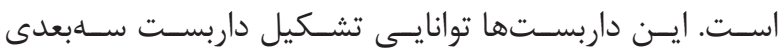

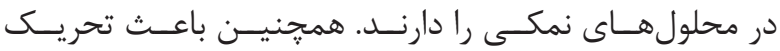

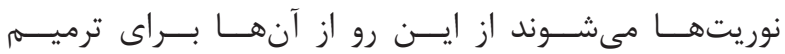

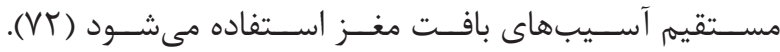

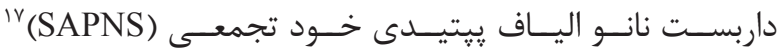

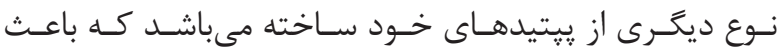

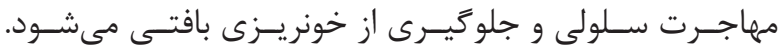

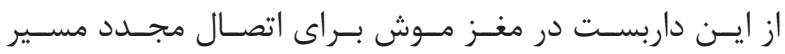

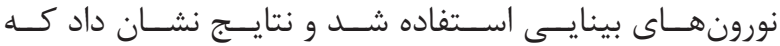

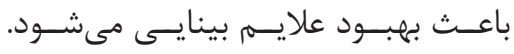

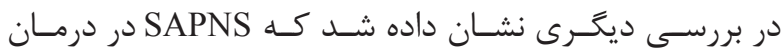

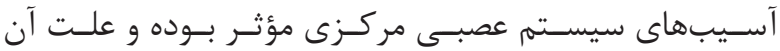

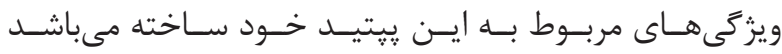

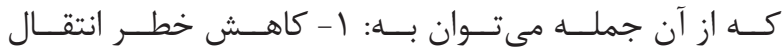

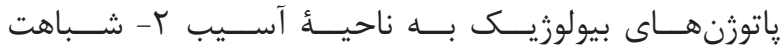

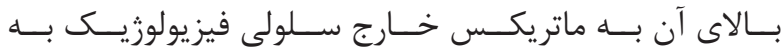

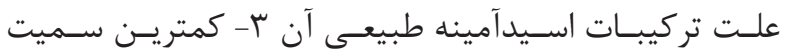

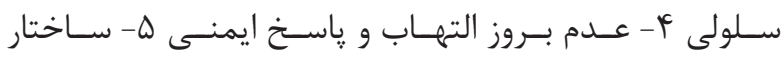

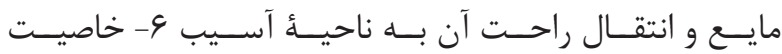

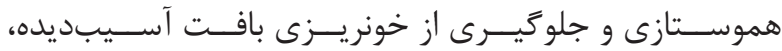

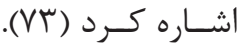

داربسـتهاى SAPNS درترميـمه آســيبهاى نخــاع، اعصـاب

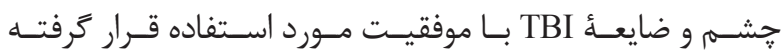

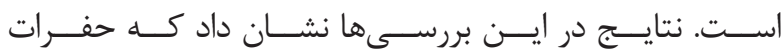

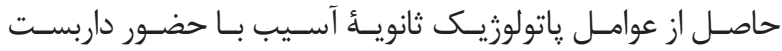

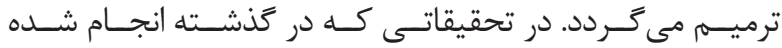

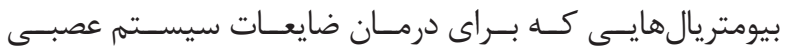

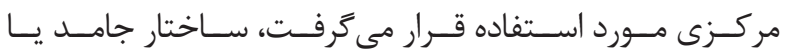

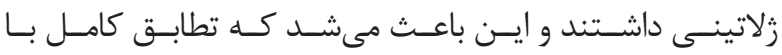

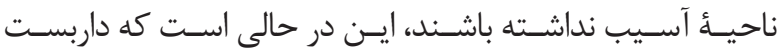

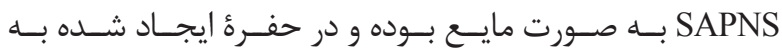

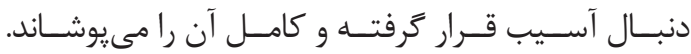

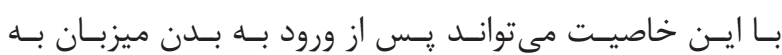

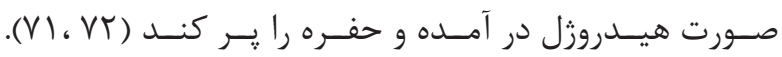

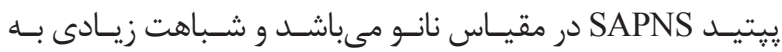

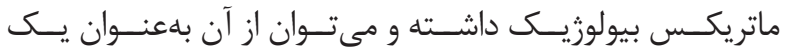

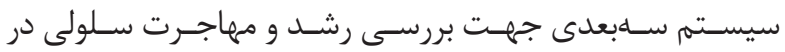

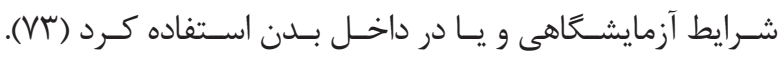

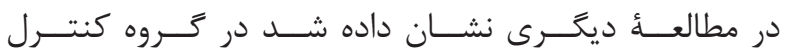

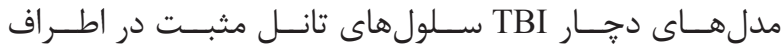

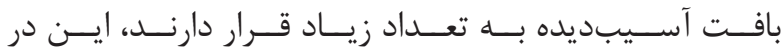

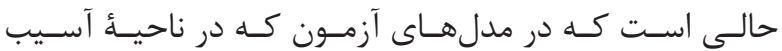

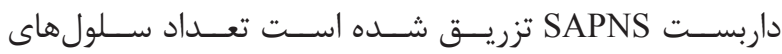

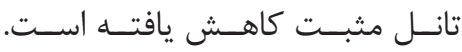

${ }^{14}$ Polyethylene glycol

${ }^{15}$ Neuroprotective

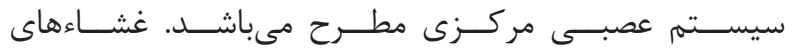

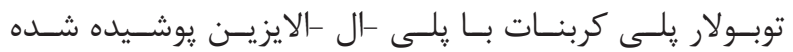

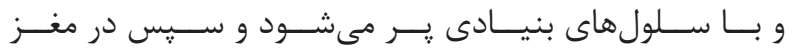

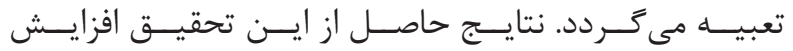

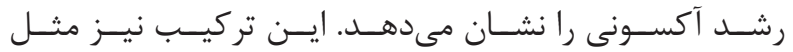

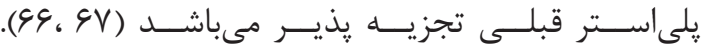

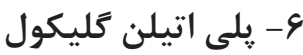

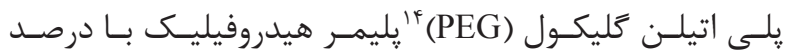

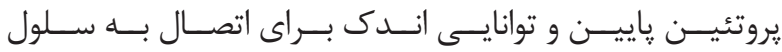

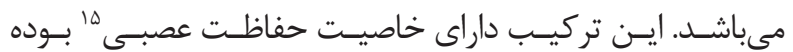

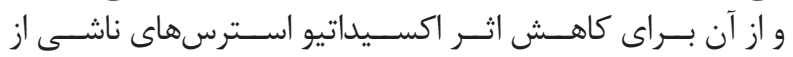

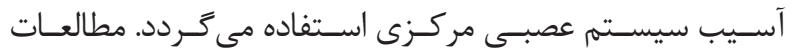

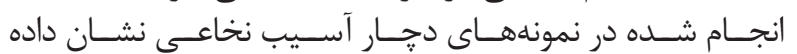

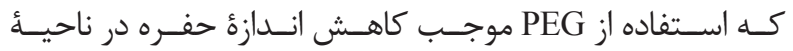

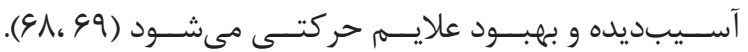

- V - Vاربست هاى پپيتيدى خود ساخته

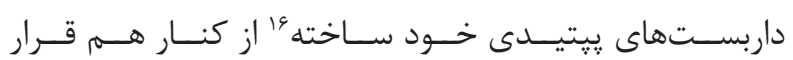

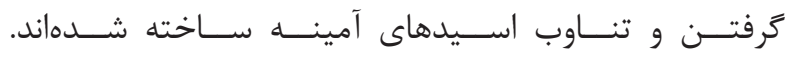

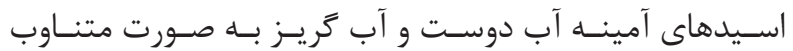

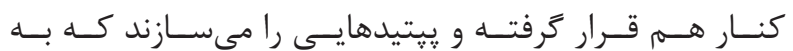

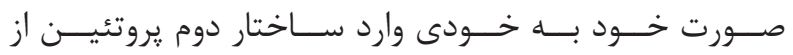

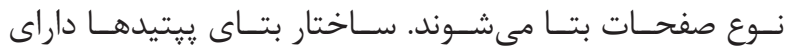

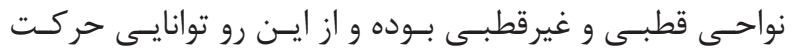

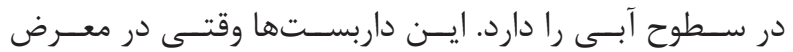

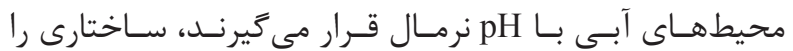

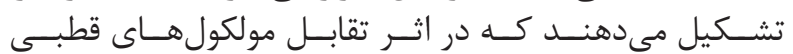

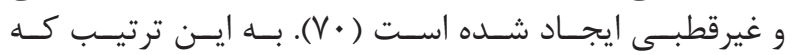

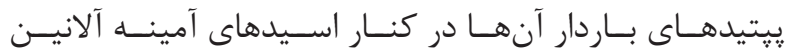

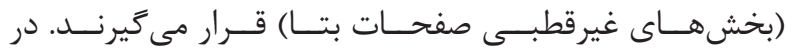

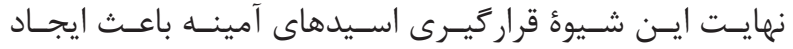

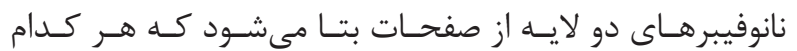

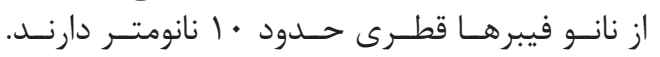

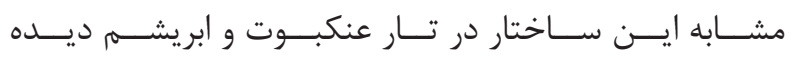

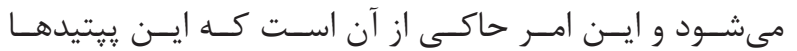

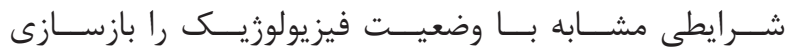

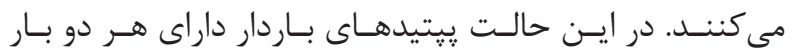

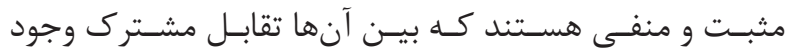

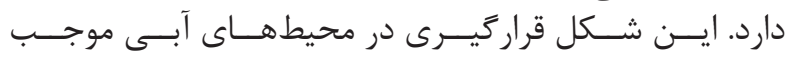

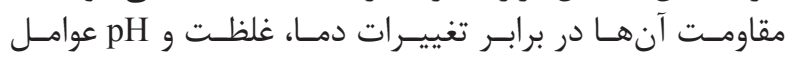

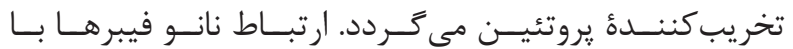

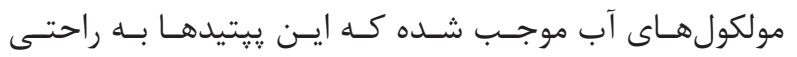

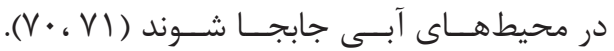

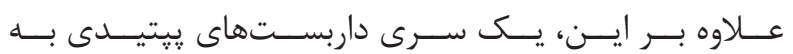

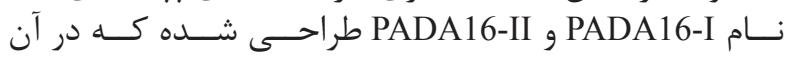

${ }^{16}$ Self-assembling peptide

${ }^{17}$ Self-assembling peptide nanofiber scaffold 
جدول r- انواع داربستهاى صناعى و كاربرد آنها درترميم آسيبهاى سيستم عصبى مركزى.

\begin{tabular}{|c|c|c|}
\hline \multicolumn{3}{|c|}{ اثواع داربستهاي صناعى } \\
\hline منابع & كاربرد داربستهاى صناعى در سيستم عصبى مركزي & ثمونهماى شناخته \\
\hline$(\Delta \mathrm{V}, \Delta \Lambda)$ & 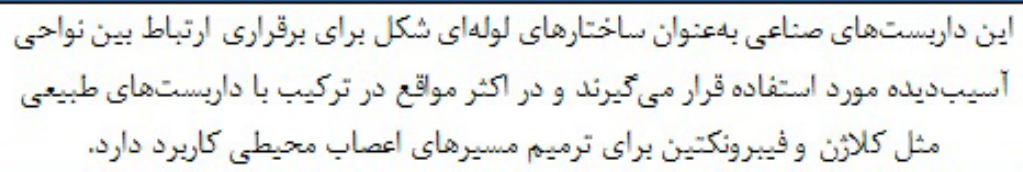 & $\begin{array}{l}\text { هلى لاكتيك اسيد } \\
\text { (PLA) }\end{array}$ \\
\hline$\left(\Delta q_{6}, \varphi_{\cdot}\right)$ & 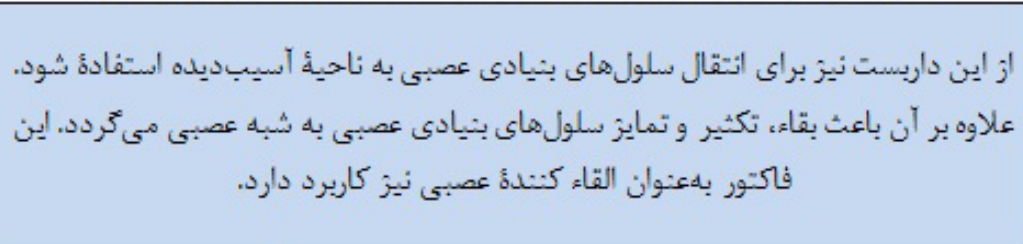 & 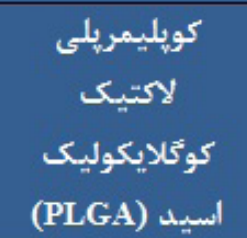 \\
\hline$(91.95)$ & 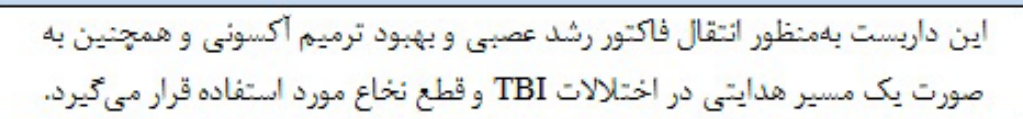 & PCL \\
\hline$(99.9 \mathrm{~V})$ & 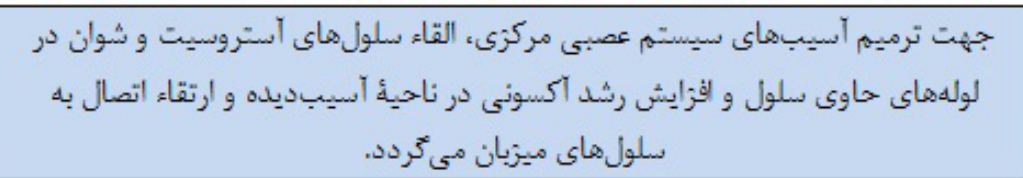 & 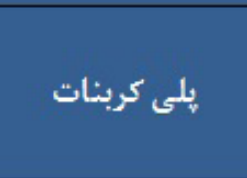 \\
\hline$(91,99)$ & خاصيت حفاظت عصبى، مقاومت در برابر آسيبهاى اكسيداتيو و كاهش مرث سلولى، & $\begin{array}{l}\text { يلى اتيلي تحليكول } \\
\text { (PEG) }\end{array}$ \\
\hline$(V I, V T)$ & 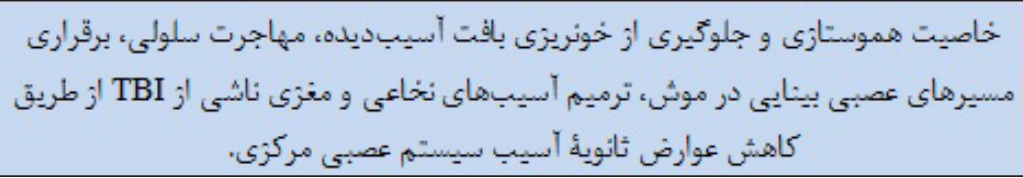 & ماربستهاى بيتيدى خود \\
\hline
\end{tabular}

جدول بـ - انواع داربستهاى تركيبى و كاربرد آنها درترميم آسيبهاى سيستم عصبى مركزى.

\begin{tabular}{|c|c|c|}
\hline \multicolumn{3}{|c|}{ اثواع داربستهاي تركيبى } \\
\hline منابع & كاربرد داربستهاى تركيبى (طبيعى -صناعى) در سيستم عصبى مركزى & نمونهماي شناخته \\
\hline$(V \Delta)$ & 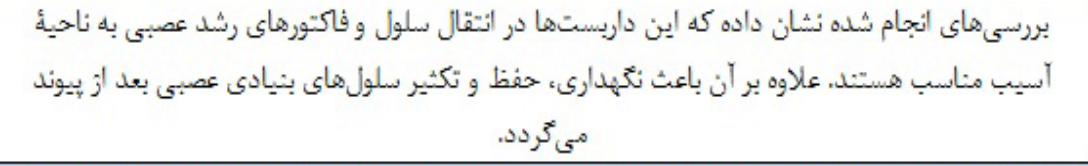 & $\begin{array}{c}\text { + PLGA } \\
\text { هيالورونيك اسيد }\end{array}$ \\
\hline$(\sqrt{9})$ & 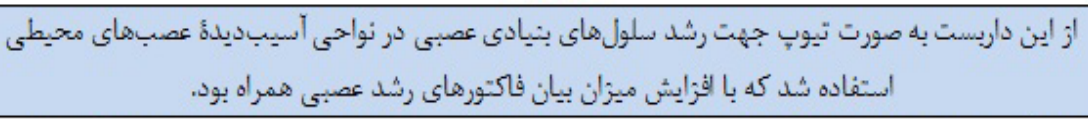 & كلارثن + PCL \\
\hline$(V V)$ & در آسيبهاى مغزى و باعث الفزايش رشد آكسونى در ناحية آسيبديده و ارتقاء اتصال به سلولهاى ميزبان & هيدروزل + لامينين \\
\hline$(\mathrm{V} \Lambda)$ & در آسيبهاي مغزى و باعث الفزايش رشد آكسونى مى كُردد. & 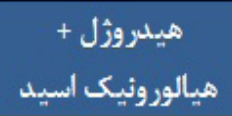 \\
\hline (V৭) & استفادةُ تركيبى أز سلولهاى مزانشيمى و اسكافولد باهنظور بهبود ضايعأ عصبى. & SwCNTs \\
\hline$(\Lambda \cdot)$ & همراه با بيوند سلول استفاده شد. & 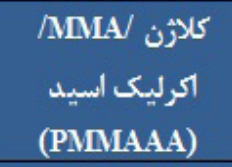 \\
\hline (A) & همراه با بيوند سلول استفاده شد. & يلى لإكتيك اسيد | لإيرولاكتون \\
\hline$(A T)$ & همراه با ي بيوند سلول استفاده شد. & 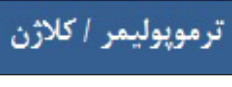 \\
\hline
\end{tabular}




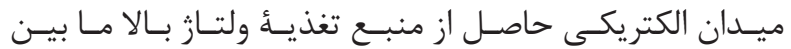

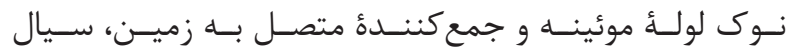

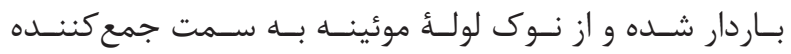

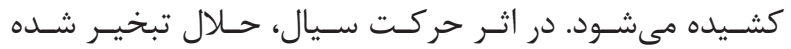

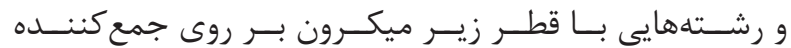

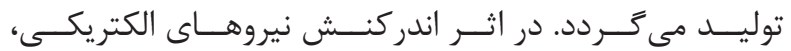

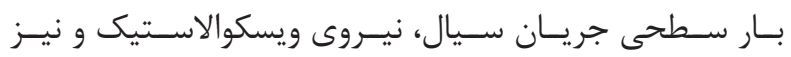

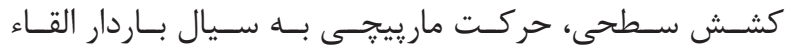

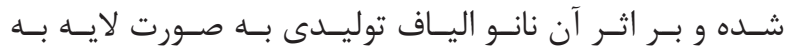

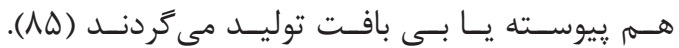

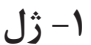

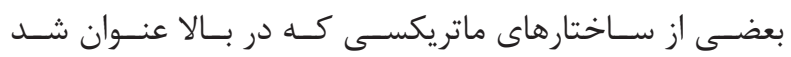

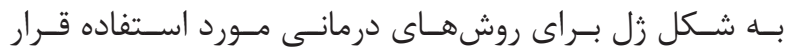

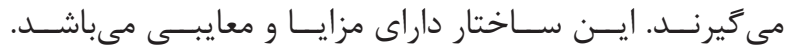

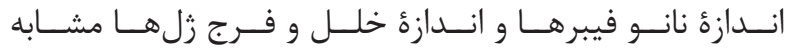

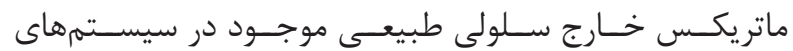

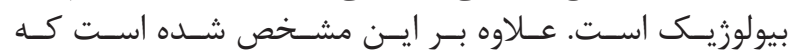

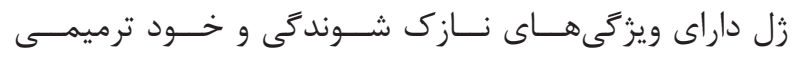

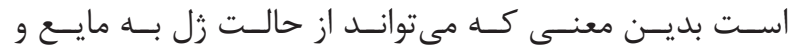

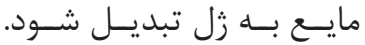

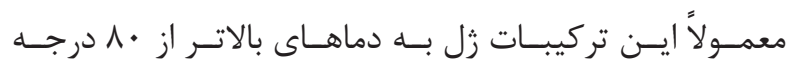

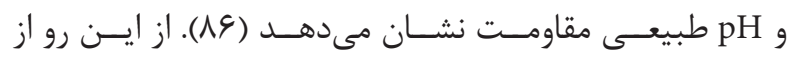

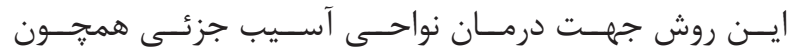

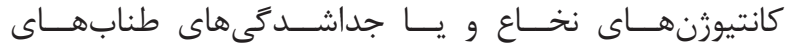

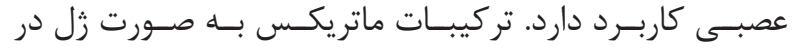

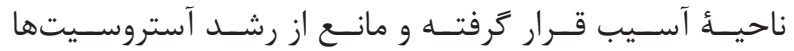

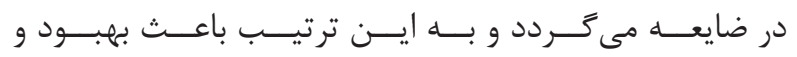

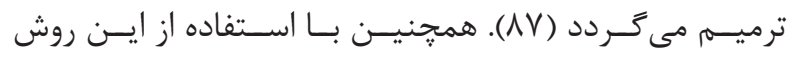

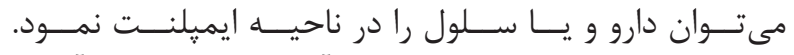

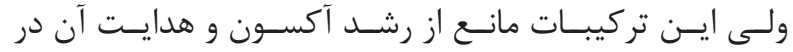

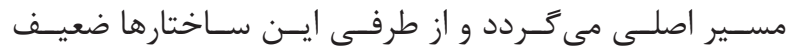

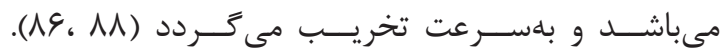

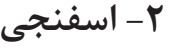

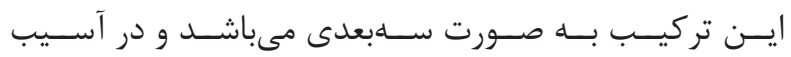

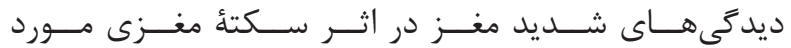

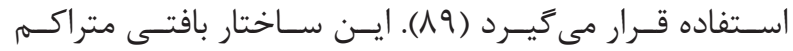

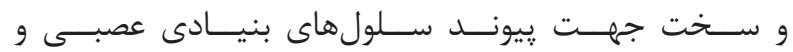

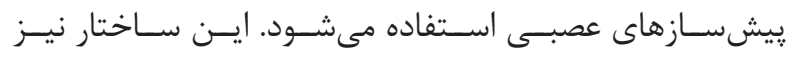

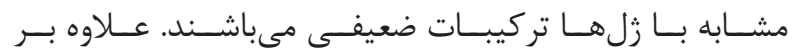

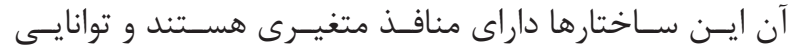

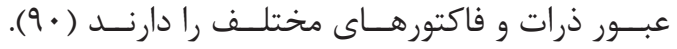

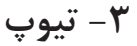

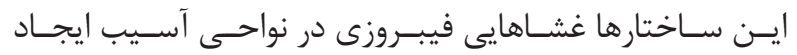

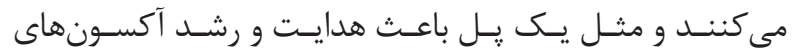

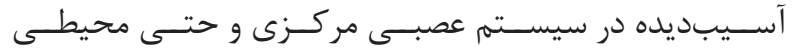

نتايـج حاصـل از ايـن تحقيـق نشـان مي دهـــ كـه SAPNS

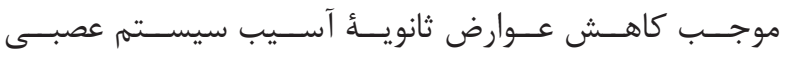

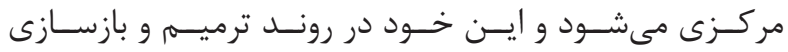

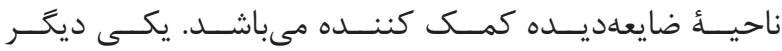

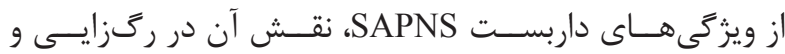

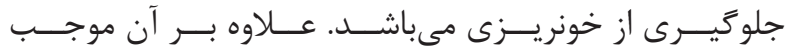

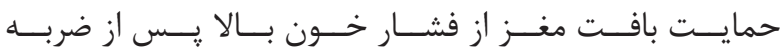

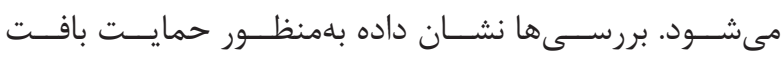

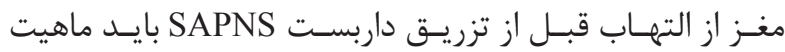

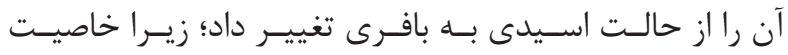

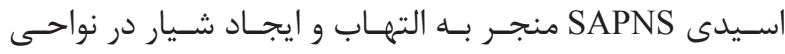

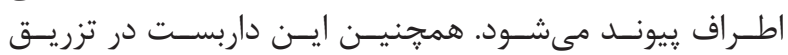

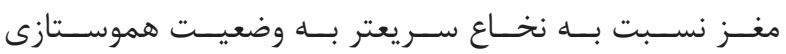

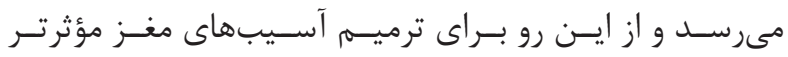

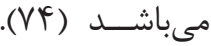

ساختار داربست طراحى شده جهت ترميم سيستم

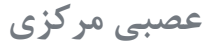

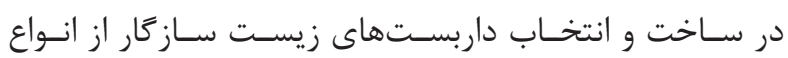

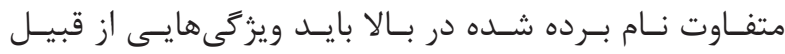

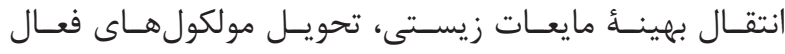

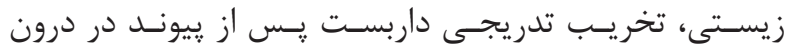

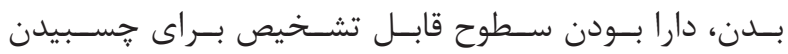

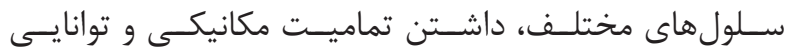

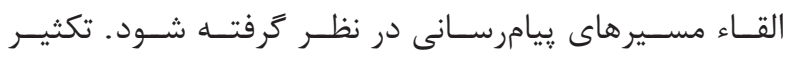

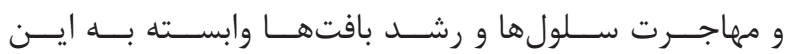

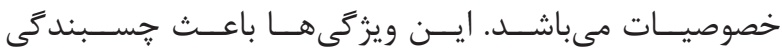

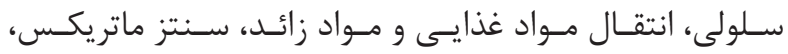

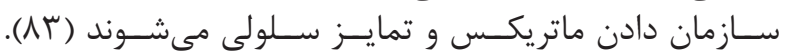

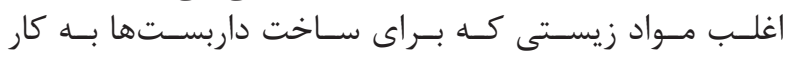

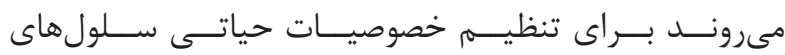

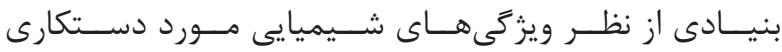

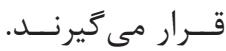

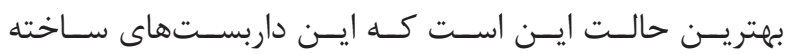

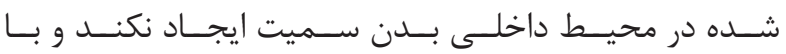

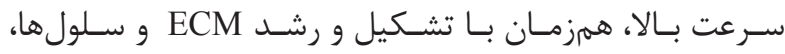

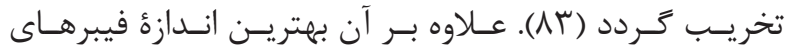

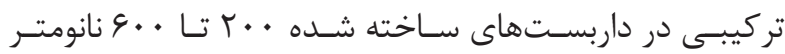

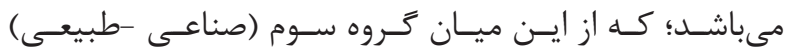

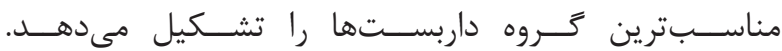

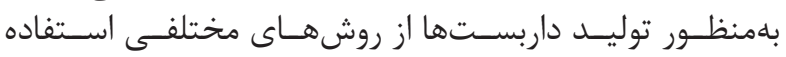

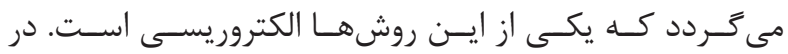

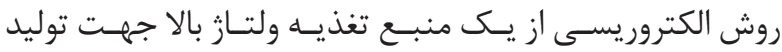

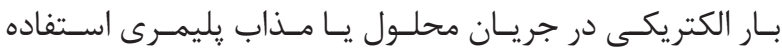

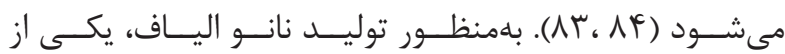

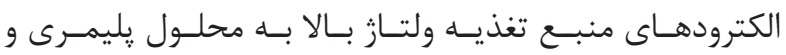

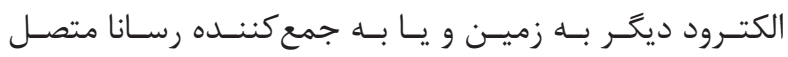

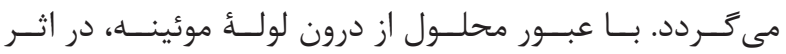




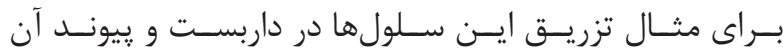

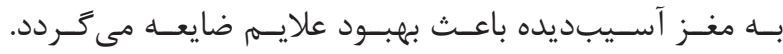

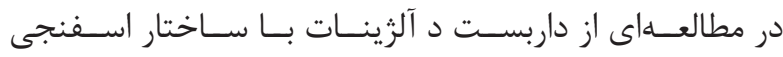

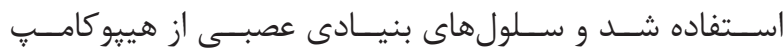

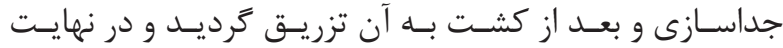

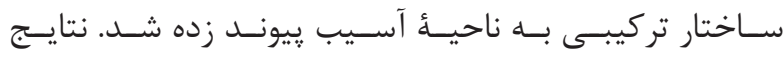

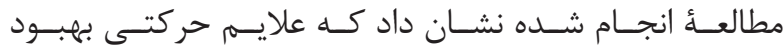

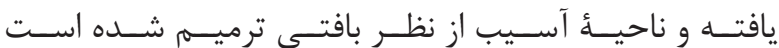

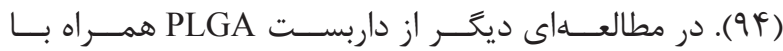

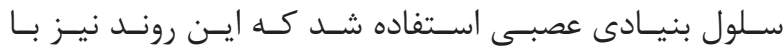

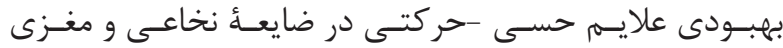

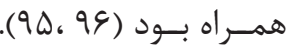

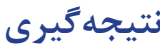

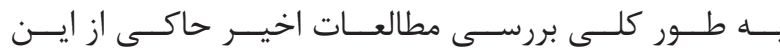

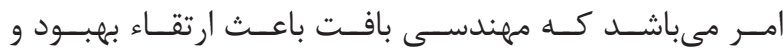

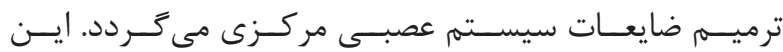

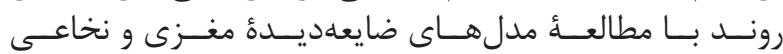

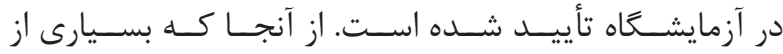

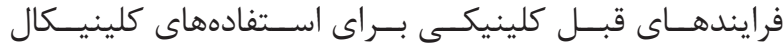

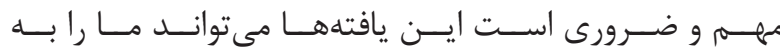

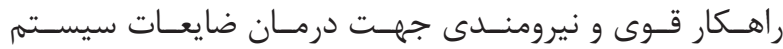

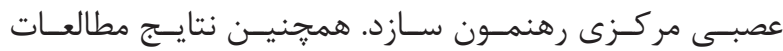

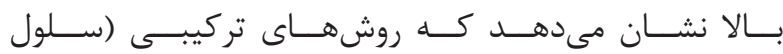

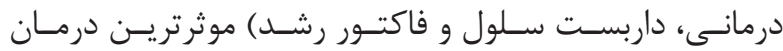

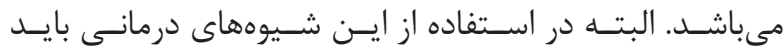

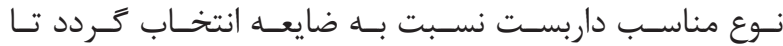

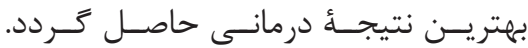

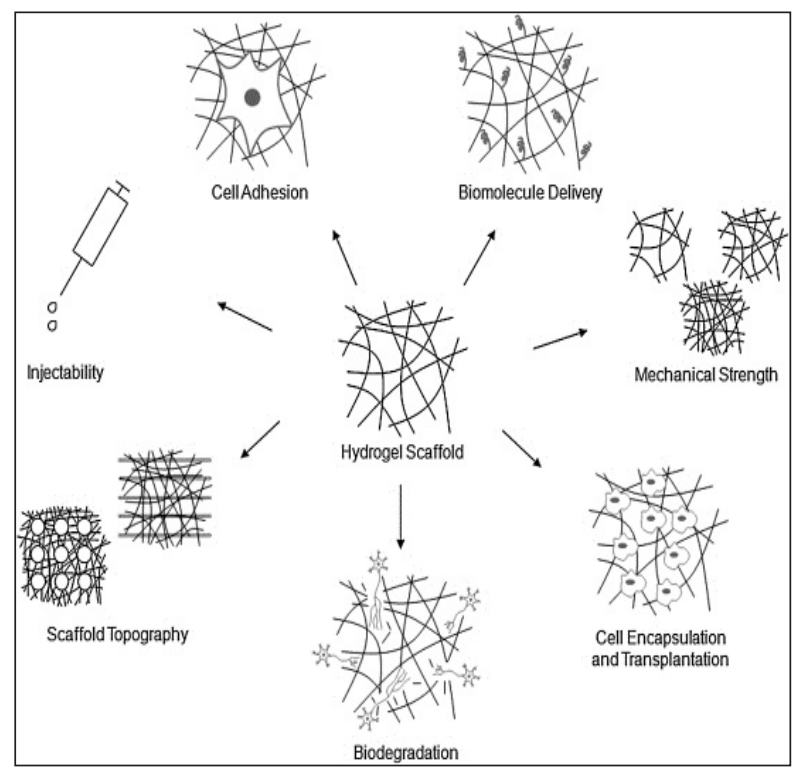

تصوير F - طراحى ساختارهاى كليدى در توليد داربست هاى هيدروزل (نوع تركيبى)-( ب9).

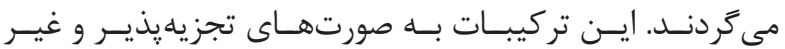

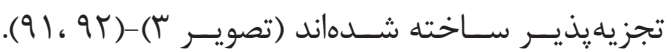

$$
\text { راهبردهاى تركيبى در كاربرد مهيندسى بافت }
$$

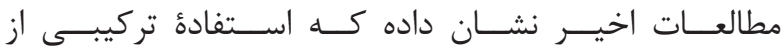

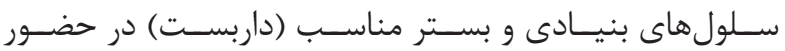

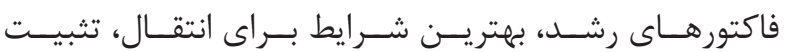

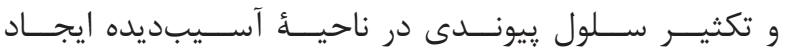

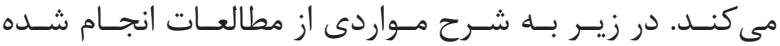

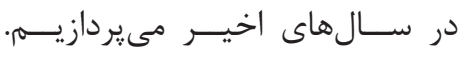

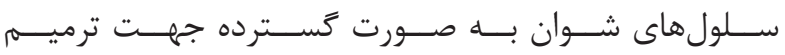

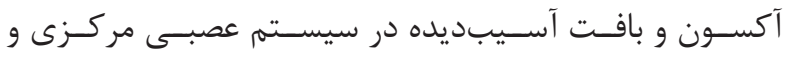

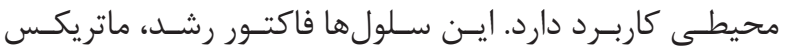

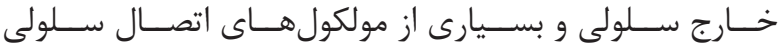

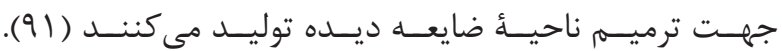

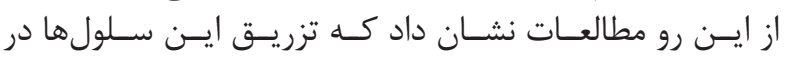

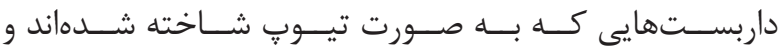

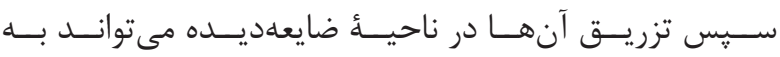

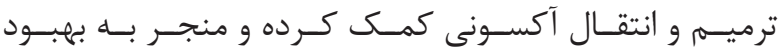

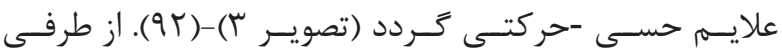

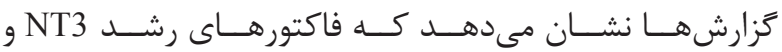

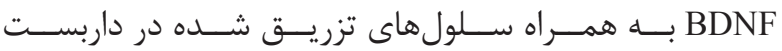

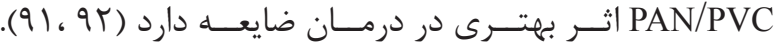

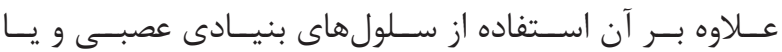

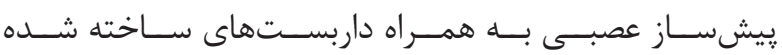

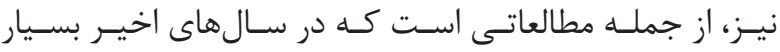

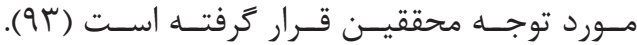

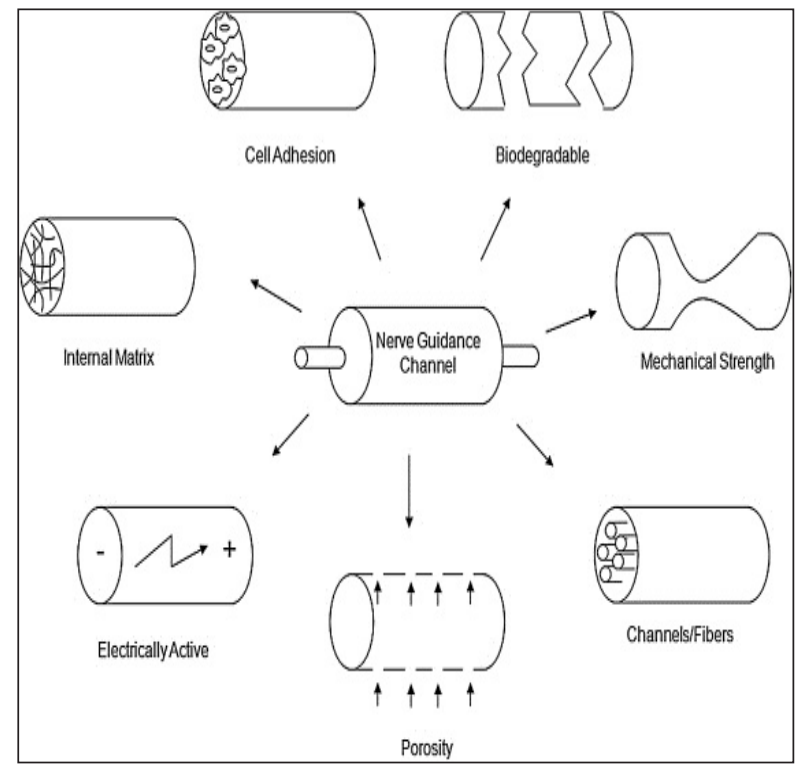

تصوير ץ - طراحى كليدى ساختارهاى مربوط به ايجاد مسير هدايت عصبى داربست (بوج). 
1. Jones LL, Oudega M, Bunge MB, Tuszynski MH. Neurotrophic factors, cellular bridges and gene therapy for spinal cord injury. J Physiol. 2001; 533(1): 83-9.

2. Darvishi M, Tarihi T, Delshad AR, Mesbah Namin AR, Taheri T. Evaluating the function of motoneuron-like cells differentiated from rat adipose derived stem cells through calcium ion imaging and investigating the synaptic vesicle recycling. Pejouhandeh. 2013; 18(5): 254-66.

3. Beattie MS, Li Q, Bresnahan JC. Cell death and plasticity after experimental spinal cord injury. Prog Brain Res. 2000; 128: 9-21.

4. Huber AB, Schwab ME. Nogo-A, a potent inhibitor of neurite outgrowth and regeneration. Biol Chem. 2000; 381(5-6): 407-19.

5. Fawcett JW, Asher RA. The glial scar and central nervous system repair. Brain Res Bull. 1999; 49(6): 37791.

6. Darvishi M, Tiraihi T, Taheri T. Treatment of spinal cord injury using transplantation of motoneurons derived from adipose stem cells following histone deacetylases inhibitors therapy in acute phase. Shefaye Khatam. 2015; 2 (3): 114.

7. Webb AA, Ngan S, Fowler D. Spinal cord injury II: prognostic indicators, standards of care, and clinical trials. Can Vet J. 2010; 51(6): 598-604.

8. Darvishi M, Tiraihi T, Taheri T. Combined treatment of spinal cord injury using transplantation of motoneurons derived adipose stem cells and adipose mesenchymal stem cells transfected with GDNF following valproic acid treatment. Shefaye Khatam. 2015; 2 (3): 118.

9. Alsberg E, Anderson KW, Albeiruti A, Rowley JA, Mooney DJ. Engineering growing tissues. Proc Natl Acad Sci U S A. 2002; 99(19): 12025-30.

10. Rose FR, Oreffo RO. Bone tissue engineering: hope vs hype. Biochem Biophys Res Commun. 2002; 292: 1-7.

11. Barati P, Tiraihi T, Darvishi M, Kazemi H. P77: cell therapy approaches to enhancing neuro-regeneration after spinal cord injury: generation neural stem cells from neurosphere-derived adipose stem cells using bioactive substance TNT. Shefaye Khatam. 2015; 2 (3): 127.

12. Avellino AM, Hart D, Dailey AT, Mackinnon M, Ellegala D, Kliot M. Differential macrophage responses in the peripheral and central nervous system during wallerian degeneration of axons. Exp Neurol. 1995; 136(2): 183-98.

13. Blesch A, Tuszynski MH. Cellular GDNF delivery promotes growth of motor and dorsal column sensory axons after partial and complete spinal cord transections and induces remyelination. J Comp Neurol. 2003; 467(3): 403-17.

14. Khojasteh A, Behnia H, Dashti SG, Stevens M. Current trends in mesenchymal stem cell application in bone augmentation: a review of the literature. J Oral Maxillofac Surg. 2012; 70(4): 972-82.

15. Darvishi M, Tiraihi T, Taheri T. Treatment of spinal cord injury using transplantation of adipose mesenchymal stem cells transfected with poly-1lysine/ DNA (GDNF)-super paramagnetic iron oxide nanoparticles. Shefaye Khatam. 2015; 2 (3): 115.

16. Barati $\mathrm{P}$, Darvishi $\mathrm{M}$, Tiraihi $\mathrm{T}$, Doroudi $\mathrm{T}$. Neurogenic differentiation of rat bone marrow stromal cells by the non toxic factors of bioactive substance as an inducer. Shefaye Khatam. 2014; 2 (2): 47-55.

17. Blesch A, Tuszynski MH. Transient growth factor delivery sustains regenerated axons after spinal cord injury. J Neurosci. 2007; 27(39): 10535-45.

18. Bloch J, Fine EG, Bouche N, Zurn AD, Aebischer P. Nerve growth factor and neurotrophin-3 releasing guidance channels promote regeneration of the transected rat dorsal root. Exp Neurol. 2001; 172(2): 425-32.

19. Borgens RB, Roederer E, Cohen MJ. Enhanced spinal cord regeneration in lamprey by applied electric fields. Science. 1981; 213(4508): 611-7.

20. Zhang S. Designer self-assembling peptide nanofiber scaffolds for study of 3-D cell biology and beyond. Adv Cancer Res. 2008; 99: 335-62.

21. Chen MS, Huber AB, van der Haar ME, Frank M, Schnell L, Spillmann AA, et al. Nogo-A is a myelin-associated neurite outgrowth inhibitor and an antigen for monoclonal antibody IN-1. Nature. 2000; 403(6768): 434-9.

22. Bhatheja K, Field J. Schwann cells: origins and role in axonal maintenance and regeneration. Int. J Biochem Cell Biol. 2006; 38(12): 1995-9. 
23. Greenwald SE, Berry CL. Improving vascular grafts: the importance of mechanical and haemodynamic properties. J Pathol. 2000; 190(3): 292-9.

24. Dodla MC, Bellamkonda RV. Differences between the effect of anisotropic and isotropic laminin and nerve growth factor presenting scaffolds on nerve regeneration across long peripheral nerve gaps. Biomaterials. 2008; 29(1): 33-46.

25. Fine EG, Valentini RF, Bellamkonda R, Aebischer $\mathrm{P}$. Improved nerve regeneration through piezoelectric vinylidene fluoride-trivfluoroethylene copolymer guidance channels. Biomaterials. 1991; 12(8): 775-80.

26. Hynds DL, Snow DM. Neurite outgrowth inhibition by chondroitin sulfate proteoglycan: stalling=stopping exceeds turning in human neuroblastoma growth cones. Exper Neurol. 1999; 160(1): 244-55.

27. Ijkema-Paassen J, Jansen K, Gramsbergen A, Meek MF. Transection of peripheral nerves, bridging strategies and effect evaluation. Biomaterials. 2004; 25(9): 1583-92.

28. Itoh S, Takakuda K, Kawabata S, Aso Y, Kasai K, Itoh $\mathrm{H}$, et al. Evaluation of cross-linking rocedures of collagen tubes used in peripheral nerve repair. Biomaterials. 2002; 23(23):4475-81.

29. Abbott A. Cell culture: biology's new dimension. Nature. 2003; 424: 870-2.

30. Lee J, Cuddihy MJ, Kotov NA. Three-dimensional cell culture matrices: state of the art. Tissue Eng Part B Rev. 2008; 14(1): 61-86.

31. Lavik E, Langer R. Tissue engineering:current state and perspectives. Applied Microbiol Biotechnol. 2004; 65(1): $1-8$.

32. Ruoslahti E, Pierschbacher MD. New perspectives in cell adhesion: RGD and integrins. Science. 1987; 238(4826): 491-7.

33. Ruoslahti E. Fibronectin and its receptors. Annu Rev Biochem. 1988; 57: 375-413.

34. Yamada KM. Adhesive recognition sequences. J Biol Chem. 1991; 266(20): 12809-12.

35. Scott M, Matsudaira P, Lodish H, Darnell J, Zipursky L, Kaiser C, et al. Molecular cell biology. $5^{\text {th }}$ ed. San Francisco: CA WH Freeman. 2003; p. 549-56.

36. Alberts B, Johnson A, Lewis J, Raff M, Roberts K, Walter P. Molecular biology of the cell. $4^{\text {th }}$ ed. New York: Garland Publishing. 2002; p. 493-7.
37. Pampaloni F, Reynaud EG, Stelzer EHK. The third dimension bridges the gap between cell culture and live tissue. Nature Rev Mol Cell Biol. 2007; 8: 839-45.

38. Toda S, Watanabe K, Yokoi F, Matsumura S, Suzuki $\mathrm{K}$, Ootani A, et al. A new organotypic culture of thyroid tissue maintains threedimensional follicles with c cells for a long term. Biochem Biophys Res Commun. 2002; 294(4): 906-11.

39. Hadjantonakis AK, Dickinson ME, Fraser SE, Papaioannou VE. Technicolour transgenics: imaging tools for functional genomics in the mouse. Nature Rev Genet. 2003; 4(8): 613-25.

40. Timmins NE, Harding FJ, Smart C, Brown MA, Nielsen LK. Method for the generation and cultivation of functional three-dimensional mammary constructs without exogenous extracellular matrix. Cell Tissue Res. 2005; 320(1): 207-10.

41. Zuk PA. Tissue engineering craniofacial defects with adult stem cells? are we ready yet? Pediatr Res. 2008; 63(5): 478-86.

42. Galler KM, D'souza RN, Hartgerink JD, Schmalz G. Scaffolds for dental pulp tissue engineering. Adv Dent Res. 2011; 23(3): 333-9.

43. Marchand R, Woerly S, Bertrand L, Valdes N. Evaluation of two cross-linked collagengels implanted in the transected spinal cord. Brain Res Bull. 1993; 30(3-4): 415-22.

44. Shamloo A. Neuronal cell navigation within a microfluidic device. $2^{\text {nd }}$ ed. Middle East: Conference on Biomedical Engineering. 2014; p.261-4.

45. Paino CL, Bunge MB. Induction of axon growth into Schwann cell implants grafted into lesioned adult rat spinal cord. Exp Neurol. 1991; 114(2): 254-7.

46. Bunge MB. Bridging the transected or contused adult rat spinal cord with schwann cell and olfactory ensheathing glia transplants. Prog Brain Res. 2002; 137: $275-82$.

47. King VR, Phillips JB, Brown RA, Priestley JV. (2004). The effects of treatment with antibodies to transforming growth factor beta1 and beta 2 following spinal cord damage in the adult rat. Neuroscience. 2004; 126(1): 173-83.

48. Phillips JB, King VR, Ward Z, Porter RA, Priestley JV, Brown RA. Fluid shear in viscous fibronectin gels allows aggregation of fibrous materials for CNS tissue engineering. Biomaterials. 2004; 25(14): 2769-79. 


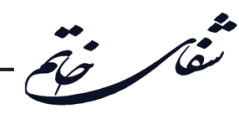

49. Suzuki Y, Kitaura M, WU S, Kataoka K, Suzuki K, Endo K, et al. Electrophysiological and horseradish peroxidase-tracing studies of nerve regeneration through alginate-filled gap in adult rat spinal cord. Neurosci Lett. 2002; 318(3): 121-4.

50. Freier T, Montenegro R, Shan-Koh H, Shoichet MS. Chitin-based tubes for tissue engineering in the nervous system. Biomaterials. 2005; 26(22): 4624-32.

51. Avitabile T, Marano F, Castiglione F, Bucolo C, Cro M, Ambrosio L, et al. Biocompatibility and biodegradation of intravitreal hyaluronan implants in rabbits. Biomaterials. 2001; 22(3): 195-200.

52. Ozgenel GY. Effects of hyaluronic acid on peripheral nerve scarring and regeneration in rats. Microsurgery. 2003; 23(6): 575-81.

53. Fergal J, O’Brien. Biomaterials \& scaffolds for tissue engineering. Biomaterials. 2011; 14(3): 88-95.

54. Yuan Y, Zhang P, Yang Y, Wang X, GU X. The interaction of Schwann cells with chitosan membranes and fibers in vitro. Biomaterials. 2004; 25(18): 4273-8.

55. Mohanna PN, Young RC, Wiberg M, Terenghi G. A composite poly-hydroxybutyrateglial growth factor conduit for long nerve gap repairs. J Anat.2003; 203(6): 553-65.

56. Novikov LN, Novikova LN, Mosahebi A, Wiberg M, Terenghi G, Kellerth JO. A novel biodegradable implant for neuronal rescue and regeneration after spinal cord injury. Biomaterials. 2002; 23(16): 3369-76.

57. Nampoothiri KM, Nair NR, John RP An overview of the recent developments in lylactide (PLA) research. Bioresour Technol. 2010; 101(22): 8493-501.

58. Bendix D. Chemical synthesis of polylactide and its copolymers for medical applications. Polym Degrad. 1998; 59(1-3): 129-35.

59. Faghihi F, Mirzaei E, Ai J, Lotfi A, Sayahpour F, Barough S, et al. Differentiation potential of human chorion-derived mesenchymal stem cells into motor neuron-like cells in two- and three-dimensional culture systems. Mol Neurobiol. 2016; 53(3): 1862-72.

60. Barough S, Javidan A, Saberi H, Joghataei MT, Rahbarghazi R, Mirzaei E, et al. Evaluation of motor neuron-like cell differentiation of hEnSCs on biodegradable PLGA nanofiber scaffolds. Mol Neurobiol. 2015; 52(3): 1704-13.

61. Pitt CG. Poly- $\varepsilon$-caprolactone and its copolymers, in biodegradable polymers as drug delivery systems. New York: Marcel Dekker. 1990; p. 71.

62. Coombes A, Rizzi S, Williamson M, Barralet J, Downes S, Wallace W. Precipitation casting of polycaprolactone for applications in tissue engineering and drug delivery. Biomaterials. 2004; 25(2): 315-25.

63. Patist CM, Mulder MB, Gautier SE, Maquet V, Jerome R, Oudega M. Freeze-dried poly (D,L-lactic acid) macroporous guidance scaffolds impregnated with brain-derived neurotrophic factor in the transected adult rat thoracic spinal cord. Biomaterials. 2004; 25(2):1569-82.

64. Day RM, Boccaccini AR, Maquet V, Shurey S, Forbes A, Gabe SM, et al. In vivo characterisation of a novel bioresorbable poly(lactide-co-glycolide) tubular foam scaffold for tissue engineering applications. J Mater Sci Mater Med. 2004; 15(6): 729-734.

65. Asti A, Gioglio L. Natural and synthetic biodegradable polymers: different scaffolds for cell expansion and tissue formation. Int $\mathbf{J}$ Artif Organs. 2014; 37: 187-274.

66. Montgomery CT, Tenaglia EA, Robson JA. Axonal growth into tubes implanted within lesions in the spinal cords of adult rats. Exp Neurol. 1996; 137(2): 277-90.

67. Montgomery CT, Robson JA. Implants of cultured Schwann cells support axonal growth in the central nervous system of adult rats. Exp Neurol. 1993; 122(1): 107-24.

68. Liu LS, Khan T, Sayers ST, Dauzvardis MF, Trausch CL. Electrophysiological improvement after co-implantation of carbon filaments and fetal tissue in the contused rat spinal cord. Neurosci Lett. 1995; 200(3): 199-202.

69. Laverty PH, Leskovar A, Breur GJ, Coates JR, Bergman RL, Widmer WR, et al. A preliminary study of intravenous surfactants in paraplegic dogs: polymer therapy in canine clinical SCI. J Neurotrauma. 2004; 21(12): 1767-77.

70. Beniash E, Hartgerink JD, Storrie H, Stendahl JC, Stupp SI. Self-assembling peptide amphiphile nanofibre matrices for cell entrapment. Acta Biomater. 2005; 1(4): 387-97.

71. Haines-Butterick L, Rajagopal K, Branco M, Salick D, Rughani R, Pilarz M, et al. Controlling hydrogelation kinetics by peptide design for threedimensional encapsulation and injectable delivery of 
cells. Proc Natl Acad Sci U S A. 2007; 104(19): 7791-6.

72. Smith AM, Williams RJ, Tang C, Coppo P, Collins RF, Turner ML, et al. Fmocdiphenylalanine selfassembles to a hydrogel via a novel architecture based on p-p interlocked b-sheets. Adv Mater. 2008; 20(1): 37-41.

73. Zhang S. Fabrication of novel biomaterials through molecular self-assembly. Nat Biotechnol. 2003; 21(10): 1171-8.

74. Jayawarna V, Ali M, Jowitt TA, Miller AF, Saiani A, Gough JE, et al. Nanostructured hydrogels for three-dimensional cell culture through self-assembly of fluorenylmethoxycarbonyl-dipeptides. Adv Mater. 2006; 18(5): 611-4.

75. Wang Y, Wei YT, Zu ZH, Ju RK, Guo MY, Wang $\mathrm{XM}$, et al. Combination of hyaluronic acid hydrogel scaffold and PLGA microspheres for supporting survival of neural stem cells. Pharm Res. 2011; 28(6): 1406-14.

76. Cao H, Liu T, Chew SY. The application of nanofibrous scaffolds in neural tissue engineering. Adv Drug Deliv Rev. 2009; 61(12): 1055-64.

77. Hackett JM. Electrospun biocomposite polycaprolactone/collagen tubes as scaffolds for neural stem cell differentiation. Materials. 2010; 3(6): 3714-28.

78. Yong JR, Zi YZ, Fu ZC, Ying W, Jun PZ, Qun YX. Hyaluronic acid/polylysine hydrogel as a transfer system for transplantation of neural stem cells. J Bioact Compat Polym. 2009; 24(1): 56-62.

79. Tian WM, Zhang CL, Hou SP, Yu X, Cui FZ, Xu QY, et al. Hyaluronic acid hydrogel as Nogo-66 receptor antibody delivery system for the repairing of injured rat brain: in vitro. J Control Release. 2005; 102(1): 13-22.

80. Lai JC, Schoen MP, Perez Gracia A, Naidu DS, Leung SW. Prosthetic devices: challenges and implications of robotic implants and biological interfaces. Proc Inst Mech Eng H. 2007; 221(2): 173-83.

81. Prabhakaran MP, Venugopal JR, Ramakrishna S. Mesenchymal stem cell differentiation to neuronal cells on electrospun nanofibrous substrates for nerve tissue engineering. Biomaterials. 2009; 30(28): 4996-5003.

82. Yow SZ, Quek CH, Yim EK, Lim CT, Leong KW. Collagen-based fibrous scaffold for spatial organization of encapsulated and seeded human mesenchymal stem cells. Biomaterials. 2009; 30(6): 1133-42.

83. Liang D, Hsiao BS, Chu B. Functional electrospun nanofibrous scaffolds for biomedical applications. Adv
Drug Deliv Rev. 2007; 59(14): 1392-412.

84. Chew SY, Wen Y, Dzenis Y, Leong KW. The role of electrospinning in the emerging field of nanomedicine. Curr Pharm. 2006; 12(36). 4751-70.

85. Medberry C, Crapo P, Siu B, Carruthers A, Wolf M, Nagarkar S, et al. Hydrogels derived from central nervous system extracellular matrix. Biomaterials. 2013; 34(4): 1033-40.

86. Crapo PM, Wang Y. Small intestinal submucosa gel as a potential scaffolding material for cardiac tissue engineering. Acta Biomater. 2010; 6(6): 2091-6.

87. Wolf MT, Daly KA, Brennan-Pierce EP, Johnson SA, Carruthers CA, D'Amore A, et al. A hydrogel derived from decellularized dermal extracellular matrix. Biomaterials. 2012; 33(29): 7028-38.

88. Narotam A, Dellen j, Bhoola K. A clinicopathological study of collagen sponge as a dural graft in neurosurgery. J Neurosurg. 1995; 82(3): 406-12.

89. Zeng X, Zeng Y, Ma Y, Lu L, Du L, Zhang W. et al. Bone marrow mesenchymal stem cells in a three-dimensional gelatin sponge scaffold attenuate inflammation, promote angiogenesis, and reduce cavity formation in experimental spinal cord injury. Cell Transplantation. 2011; 20(11-12): 1881-99.

90. Bamber NI, Li H, Lu X, Oudega M, Aebischer $\mathrm{P}, \mathrm{Xu} \mathrm{XM}$. Neurotrophins BDNF and NT-3 promote axonal re-entry into the distal host spinal cord through Schwann cell-seeded mini-channels. Eur J Neurosci. 2001; 13(2): 257-68.

91. Prokopova-Kubinova S, Vargova L, Tao L, Ulbrich K, Subr V, Syková E, et al. Poly[N-(2-hydroxypropyl) methacrylamide] polymers diffuse in brain extracellular space with same tortuosity as small molecules. Biophys J. 2001; 80(1): 542-8.

92. Ramon-Cueto A, Santos-Benito FF. Cell therapy to repair injured spinal cords: olfactory ensheathing glia transplantation. Restor Neurol Neurosci. 2001; 19(1-2): 149-56.

93. Straley KS, Foo CW, Heilshorn SC. Biomaterial design strategies for the treatment of spinal cord injuries. J Neurotrauma. 2009; 27(1): 1-19.

94. Fouad K, Schnell L, Bunge MB, Schwab ME, Liebscher T, Pearse DD. Combining Schwann cell bridges and olfactory-ensheathing glia grafts with 


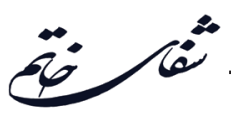

chondroitinase promotes locomotor recovery after complete transection of the spinal cord. J Neurosci. 2005; 25(5): 1169-78.

95. Iannotti C, Li H, Yan P, Lu X, Wirthlin L, Xu XM. Glial cell line-derived neurotrophic factor-enriched bridging transplants promote propriospinal axonal regeneration and enhance myelination after spinal cord injury. Exp Neurol. 2003; 183(2): 379-93.

96. Kramer M, Chaudhuri JB, Ellis MJ. Promotion of neurite outgrowth in corporation poly-l-lysine into aligned PLGA nanofiber scafolds. Europ Cell Mater. 2011; 22: 53. 